Old Dominion University

ODU Digital Commons

Biological Sciences Faculty Publications

Biological Sciences

$11-2001$

\title{
Swimming Mechanics and Behavior of the Shallow-Water Brief Squid Lolliguncula brevis
}

Ian K. Bartol

Old Dominion University, ibartol@odu.edu

Mark R. Patterson

Roger Mann

Follow this and additional works at: https://digitalcommons.odu.edu/biology_fac_pubs

Part of the Biomechanics Commons, and the Marine Biology Commons

\section{Repository Citation}

Bartol, Ian K.; Patterson, Mark R.; and Mann, Roger, "Swimming Mechanics and Behavior of the Shallow-Water Brief Squid Lolliguncula brevis" (2001). Biological Sciences Faculty Publications. 204.

https://digitalcommons.odu.edu/biology_fac_pubs/204

\section{Original Publication Citation}

Bartol, I. K., Patterson, M. R., \& Mann, R. (2001). Swimming mechanics and behavior of the shallow-water brief squid Lolliguncula brevis. Journal of Experimental Biology, 204(21), 3655-3682. 


\title{
Swimming mechanics and behavior of the shallow-water brief squid Lolliguncula brevis
}

\author{
Ian K. Bartol ${ }^{1, *}$, Mark R. Patterson ${ }^{2}$ and Roger Mann ${ }^{2}$ \\ ${ }^{1}$ Department of Organismic Biology, Ecology, and Evolution, 621 Charles E. Young Drive South, University of \\ California, Los Angeles, CA 90095-1606, USA and 2 School of Marine Science, Virginia Institute of Marine Science, \\ College of William and Mary, Gloucester Point, VA 23062-1346, USA \\ *e-mail: ikbartol@lifesci.ucla.edu
}

Accepted 6 August 2001

\begin{abstract}
Summary
Although squid are among the most versatile swimmers and rely on a unique locomotor system, little is known about the swimming mechanics and behavior of most squid, especially those that swim at low speeds in inshore waters. Shallow-water brief squid Lolliguncula brevis, ranging in size from 1.8 to $8.9 \mathrm{~cm}$ in dorsal mantle length $(D M L)$, were placed in flumes and videotaped, and the data were analyzed using motion-analysis equipment. Flow visualization and force measurement experiments were also performed in water tunnels. Mean critical swimming speeds $\left(U_{\text {crit }}\right)$ ranged from 15.3 to $22.8 \mathrm{~cm} \mathrm{~s}^{-1}$, and mean transition speeds $\left(U_{t}\right.$; the speed above which squid swim exclusively in a tail-first orientation) varied from 9.0 to $15.3 \mathrm{~cm} \mathrm{~s}^{-1}$. At low speeds, negatively buoyant brief squid generated lift and/or improved stability by

decreased angles of attack and swam tail-first. Fin motion, which could not be characterized exclusively as drag- or lift-based propulsion, was used over $50-95 \%$ of the sustained speed range and provided as much as $83.8 \%$ of the vertical and $55.1 \%$ of the horizontal thrust. Small squid $(<3.0 \mathrm{~cm} D M L)$ used different swimming strategies from those of larger squid, possibly to maximize thrust benefits from vortex ring formation. Furthermore, brief squid employed various unsteady behaviors, such as manipulating funnel diameter during jetting, altering arm position and swimming in different orientations, to boost swimming performance. These results demonstrate that locomotion in slow-swimming squid is complex, involving intricate spatial and temporal interactions between the mantle, fins, arms and funnel.
\end{abstract} positioning the mantle and arms at high angles of attack, directing high-speed jets downwards (angles $>50^{\circ}$ ) and using fin activity. To reduce drag at high speeds, the squid

Key words: squid, negative buoyancy, hydrodynamics, swimming, jet propulsion, Lolliguncula brevis, fin.

\section{Introduction}

Resistive and propulsive forces associated with jet propulsion have been investigated in scallops (Trueman, 1975; Vogel, 1985; Dadswell and Weihs, 1990; Millward and Whyte, 1992; Cheng and DeMont, 1996; Cheng et al., 1996), jellyfish (Daniel, 1983; Daniel, 1985; DeMont and Gosline, 1988), salps (Madin, 1990) and frogfishes (Fish, 1987). The bestknown jetters are cephalopods, including the chambered Nautilus, octopuses, cuttlefishes and squid. Much of the hydrodynamic work on cephalopods has been performed on Nautilus and centers around the effects of the shell on surrounding flow, locomotion and mode of life (Raup, 1967; Chamberlain and Westerman, 1976; Chamberlain, 1976; Chamberlain, 1980; Chamberlain, 1981; Chamberlain, 1990; Holland, 1987; O'Dor et al., 1990). Although there are a number of papers examining swimming energetics of squid (O'Dor, 1982; Webber and O'Dor, 1985; Webber and O'Dor, 1986; O'Dor and Webber, 1986; O'Dor and Webber, 1991; O’Dor et al., 1994; Finke et al., 1996), only Johnson et al. (Johnson et al., 1972), O’Dor (O'Dor, 1988) and Anderson and
DeMont (Anderson and DeMont, 2000) focus on the hydrodynamics and mechanics of squid locomotion. Johnson et al. (Johnson et al., 1972) outline a theoretical approach to squid swimming, but it has limited applicability since it is based on one contraction of the mantle musculature and incorporates a number of oversimplifications and assumptions. O'Dor (O'Dor, 1988) provides a more in-depth and informative examination of the forces acting on adult squid Loligo opalescens (and to a lesser extent Illex illecebrosus) using video analysis and recordings of mantle cavity pressure. Anderson and DeMont (Anderson and DeMont, 2000) provide interesting information on propulsive efficiency and some unsteady hydrodynamics of adult Loligo pealei.

The limited research on squid swimming mechanics is surprising given the versatility of squid as swimmers. Squid may hover in one spot, change direction rapidly with apparent ease, stop and reverse direction and ascend and descend almost vertically. Squid are capable of such impressive maneuvers because of interactions between three systems: (i) the jet, 
which may be directed using a funnel maneuverable within a hemisphere below the body, (ii) the fins, which may undulate and/or flap independently or synchronously, and (iii) the arms, which may be positioned at different angles of attack, moved vertically and laterally and extended and retracted to maximize and minimize surface area.

Although O'Dor (O'Dor, 1988) and Anderson and DeMont (Anderson and DeMont, 2000) provide important information on moderately large squid species, which swim at moderate to high speeds and rely heavily on the jet for propulsion, several important areas of locomotion in squid remain unexplored. (i) Little is known about how swimming mechanics change with size in squid. With the exception of some general observations on Illex illecebrosus hatchlings in aquaria (O'Dor et al., 1985), all hydrodynamic work on squid has focused on adults of similar size. (ii) Squid are capable of swimming in two orientations: tail-first, in which the posterior closed end of the mantle and fins are located at the leading edge and the arms trail behind, and arms-first, in which the arms are at the leading edge and the fins and mantle trail behind. However, very little is known about arm-first swimming, which is frequently observed in the field and in captivity (Hanlon et al., 1983; Vecchione and Roper, 1991) and is the primary swimming mode used for prey capture (Hanlon and Messenger, 1996; Kier and van Leeuwen, 1997). (iii) Although the effects of unsteady flow play integral roles in force and lift generation in other aquatic organisms (Daniel, 1983; Daniel, 1984; Daniel, 1988; Dickinson, 1996; Westneat, 1996; Müller et al., 1997; Drucker and Lauder, 1999; Dickinson et al., 2000), unsteady flow effects on squid, which swim in a pulsatile fashion, have received little attention, with the notable exception of a recent study by Anderson and DeMont (Anderson and DeMont, 2000). (iv) Little is known about the swimming mechanics of slow-moving squid, which maneuver in complex, inshore environments and appear to use considerable fin motion. (v) Finally, the role of the arms in locomotion and the interactions between the funnel, fins and arms while swimming are not fully understood.

The brief squid Lolliguncula brevis differs in ecology and physiology from the squid Loligo opalescens, Loligo pealei and Illex illecebrosus considered in past hydrodynamic studies and is an excellent candidate with which to investigate the issues described above. The brief squid is the only cephalopod known typically to inhabit low-salinity estuaries (Vecchione, 1991; Bartol et al., 2001a). Using physiological mechanisms we do not yet fully understand, it is capable of tolerating salinities as low as $17.5 \%$ under laboratory conditions (Hendrix et al., 1981; Mangum, 1991). Brief squid have short rounded bodies, large rounded fins, third arms with heavy keels and often reside in shallow, complex, temporally variable environments (Hixon, 1980; Bartol et al., 2001a). Conversely, Loligo opalescens, Loligo pealei and Illex illecebrosus are larger, more elongate and reside in deeper, more pelagic regions (Hixon, 1980; Hixon, 1983; O’Dor, 1983; Hanlon and Messenger, 1996). While Illex illecebrosus and Loligo opalescens frequently swim at moderate to high speeds
(50-100 $\mathrm{cm} \mathrm{s}^{-1}$ ) (O'Dor, 1982; O'Dor, 1988; Webber and O'Dor, 1986) and use their fins primarily for maneuvering and steering (O'Dor, 1988; Hoar et al., 1994), L. brevis appears to swim at lower speeds $\left(<30 \mathrm{~cm} \mathrm{~s}^{-1}\right)$, uses considerable fin activity and swims readily in either an arms-first or a tail-first orientation (Bartol et al., 2001b). Moreover, there is metabolic evidence suggesting that brief squid have high swimming costs at low speeds because of negative buoyancy and have parabolic oxygen consumption/speed relationships (Bartol et al., 2001b), which to date have not been detected in Illex illecebrosus, Loligo opalescens and Loligo pealei.

To provide insight into how size, swimming orientation, unsteady phenomena, fin activity, arm motion and other behaviors affect the swimming mechanics of slow-swimming squid, brief squid Lolliguncula brevis of various sizes swimming in flumes were videotaped, and the footage was analyzed using motion-analysis equipment. Subsequent hydrodynamic calculations were based on these data. Flow visualization and force measurement experiments using live squid and/or models were also performed to investigate particular aspects of swimming, such as the characteristics of the jet wake and the magnitude of lift and drag forces. Because brief squid appear to possess a unique parabolic relationship between oxygen consumption rate and speed and appear to swim over a more restricted speed range than other squid examined to date, particular emphasis was placed on the effects of speed on swimming mechanics.

\section{Materials and methods \\ Experimental animals}

From May to November 1996-1998, brief squid Lolliguncula brevis (Blainville) were captured by trawl within embayments along the seaside of Virginia's Eastern Shore and within the Chesapeake Bay near Kiptopeke, Virginia. Squid captured along the Eastern Shore of Virginia were transported to the Virginia Institute of Marine Science (VIMS) Eastern Shore Laboratory in Wachapreague, Virginia, while squid captured in the Chesapeake Bay were transported to the VIMS main campus in Gloucester Point, Virginia. Squid were kept alive in the field using 1141 coolers equipped with filtration and aeration systems, which were powered by sealed rechargeable batteries. At Wachapreague and Gloucester Point, squid were kept in flow-through raceway tanks for at least 1 week prior to experimentation and fed ad libitum on a diet of grass shrimp Palaemonetes pugio. In total, 32 squid ranging from 1.8 to $8.9 \mathrm{~cm}$ in dorsal mantle length $(D M L)$ were examined for this study.

\section{Flow tunnels}

Three flumes were used for live animal work; flume selection depended on capture location and squid size. Squid less than $3.0 \mathrm{~cm}$ in $D M L$ were examined in a portable 161 recirculating flume (Vogel and LaBarbera, 1978) with a $10 \mathrm{~cm} \times 10 \mathrm{~cm} \times 75 \mathrm{~cm}$ working section. Flow velocity was controlled in the tunnel with two propellers in a rotor-stator 
configuration powered by a $187 \mathrm{~W}(0.25$ horse power) variablespeed motor. Experiments on larger squid captured at Wachapreague and Gloucester Point, Virginia, were conducted in a $5 \mathrm{~m}$ long, gravity-fed recirculating flume with a $35 \mathrm{~cm} \times 50 \mathrm{~cm} \times 100 \mathrm{~cm}$ working section [for a description, see Orth et al. (Orth et al., 1994)] and a $3 \mathrm{~m}$ long Vogel/LaBarberatype flume with a $15 \mathrm{~cm} \times 20 \mathrm{~cm} \times 100 \mathrm{~cm}$ working section [see Patterson (Patterson, 1984)], respectively. To calibrate velocity settings and to determine boundary layer thickness in each of the three flumes, flow velocities were measured from the flume floor to the water surface (in $1.0 \mathrm{~cm}$ increments) over a range of motor/valve settings using an acoustic Doppler velocimeter (ADV) (Son-Tek, Inc., San Diego, CA, USA).

\section{Critical and transition swimming speeds}

Lolliguncula brevis $(N=32)$ were allowed to acclimate to the flumes at flow velocities of 6-9 $\mathrm{cm} \mathrm{s}^{-1}$ until they were capable of swimming steadily against the flow, which generally occurred within $15 \mathrm{~min}$. After the acclimation period, squid were exposed to a flow velocity of $3 \mathrm{~cm} \mathrm{~s}^{-1}$ for $15-30 \mathrm{~min}$. Speed was subsequently increased by $3 \mathrm{~cm} \mathrm{~s}^{-1}$ every $15 \mathrm{~min}$ until the squid could no longer keep pace with free-stream flow. Critical swimming speed ( $\left.U_{\text {crit }}\right)$ was calculated using the equation (Brett, 1964):

$$
U_{\text {crit }}=U_{1}+\left[\left(T_{\mathrm{f}} / T_{\mathrm{i}}\right) U_{\mathrm{i}}\right],
$$

where $U_{1}$ is the last speed at which the squid swam for the entire $15 \mathrm{~min}$ period, $T_{\mathrm{f}}$ is the time the squid swam at the final test speed, $T_{\mathrm{i}}$ is the time spent swimming at each speed $(15 \mathrm{~min})$ and $U_{\mathrm{i}}$ is the velocity increment $\left(3 \mathrm{~cm} \mathrm{~s}^{-1}\right)$.

During the critical swimming trials, many squid swam in two different orientations: tail-first and arms-first. The transition speed $\left(U_{\mathrm{t}}\right)$ at and above which these squid swam exclusively in the tail-first orientation was recorded.

\section{Swimming kinematics}

During the 15 min swimming periods, squid were frequently videotaped using either a Sony Hi-8 or Kodak Ektapro highspeed video camera. The long axis of the camera was positioned perpendicular to the side of the flume, which provided a lateral view of the swimming squid. A mirror was also placed within the field of view of the camera above the flume at $45^{\circ}$ to provide aerial views or simultaneous aerial/lateral views of the swimming squid when necessary. Reference scales were placed on the walls and floor of the flumes for measurement calibration, but various landmarks on the squid, such as eye diameter, were often more useful calibration aids since the focal distance between the squid and camera lens varied among trials. Squid were illuminated in the flumes using both fiber-optic and $1000 \mathrm{~W}$ halogen lights. After each experiment, the squid were over-anesthetized in an isotonic solution of magnesium chloride $\left(7.5 \% \mathrm{MgCl}_{2} \cdot 6 \mathrm{H}_{2} \mathrm{O}\right)$ and sea water (Messenger et al., 1985), and wet mass out-ofwater $( \pm 0.1 \mathrm{~g})$, mass in-water (determined using a submerged spring scale) $( \pm 0.1 \mathrm{~g})$, dorsal mantle length $( \pm 0.1 \mathrm{~cm})$ and eye diameter $( \pm 0.1 \mathrm{~cm})$ were recorded. The organisms were then transferred to $10 \%$ buffered formalin. Preserved specimens were used later for wetted surface area and aspect ratio calculations. For many of the squid considered in this study, the volumes of the mantle tissue (with the fins removed) and internal viscera were measured after over-anesthesia by determining the volume of water displaced by the tissues in graduated cylinders $( \pm 0.1 \mathrm{ml})$. However, for some of the squid, this step was performed after preservation. For these squid, corrections based on volume measurements performed both before and after preservation (on other squid) were necessary to account for minor shrinkage.

Video footage of three squid within each of four size classes (1.0-2.9 cm DML, 3.0-4.9 cm DML, 5.0-6.9 cm DML and $7.0-8.9 \mathrm{~cm} D M L)$ was analyzed using a Sony EVO-9700 editing deck and a Peak Motus V.3.0 video and computer motion measurement system (Peak Performance Technologies Inc., Englewood, CO, USA). For the Hi-8 footage, the data were analyzed at 30 frames s$^{-1}$. For the high-speed footage, where as many as 1000 frames s $^{-1}$ were recorded, the data were analyzed at 32 frames s$^{-1}$. Not all the frames in the high-speed footage were analyzed because the features of interest could be followed easily at 30-32 frames s ${ }^{-1}$. For all 12 squid, $2.0-2.5 \mathrm{~s}$ of footage (3-6 jet cycles) was examined at each swimming speed (range: $3-36 \mathrm{~cm} \mathrm{~s}^{-1}$ ). At speeds at which squid swam in both tail-first and arms-first orientations, footage of swimming in both modes was analyzed. The criteria for selecting video footage were as follows: (i) the squid had to be at least $5 \mathrm{~cm}$ above the flume floor and away from the flume sides $(5 \mathrm{~cm}$ was the vertical distance above which boundary-layer effects within the tunnels were minimal on the basis of ADV measurements and at which speeds most closely matched calibration settings); (ii) the squid had to swim perpendicular to the major axis of the camera, which was determined from aerial views provided by the mirror; and (iii) the squid had to begin and end at the same horizontal position after a period of $2.0-2.5 \mathrm{~s}$ to ensure that it was swimming at a net velocity that matched the free-stream flow.

The following variables were measured on a frame-by-frame basis using the Peak Motus motion system: mantle, arm and funnel angles of attack relative to free-stream flow; funnel diameter (measured laterally at the location where water exits the funnel); mantle diameter (measured at a point $60 \%$ of the mantle length from the tail); fin-beat frequency (beats $\mathrm{s}^{-1}$ ); fin amplitude (measured at the location where chord length was greatest); speed of the trailing edge of the fin; distance above the flume bottom; swimming velocity relative to free-stream flow (calculated from eye coordinates); and acceleration. Furthermore, the time required for expansion and contraction of the mantle and the duration of the upward and downward strokes of the fins were calculated. All the above variables were measured from lateral close-up views, although one variable, mantle diameter, was also measured in footage with simultaneous lateral and aerial views to determine whether mantle expansion and contraction were uniform laterally and dorsally. To smooth out video jitter and human error during digitization, all raw coordinates were transformed using a 
fourth-order (zero-lag) Butterworth filter (Hamming, 1983). Optimal cut-off frequencies were determined using the Jackson-Knee method and did not exceed $40 \%$ of the sampling frequency (Jackson, 1979) (Peak Motus User's Guide, 1997). Although Walker (Walker, 1998) recommends a quintic spline rather than a Butterworth algorithm for biological data, the Butterworth filter consistently fitted the raw data better than either the cubic spline filter or the Fast Fourier Transform filter provided in the Peak Motus software. However, given that Walker (Walker, 1998) found that Butterworth filters may underestimate maximum accelerations by approximately $16 \%$, it at least should be mentioned that our peak accelerations may be underestimates.

\section{Flow visualization}

The velocity of water expelled from the funnel during mantle contraction was calculated by seeding the flume water with brine shrimp eggs (Argent Chemical Laboratories), videotaping the trajectory of particles ejected from the funnel using a Kodak high-speed video camera (500-1000 frames s ${ }^{-1}$ ), and calculating particle velocities using the Peak Motus motion system. In total, 10 squid ranging from 3.0 to $7.8 \mathrm{~cm} D M L$ were examined between speeds of 3.0 and $30.0 \mathrm{~cm} \mathrm{~s}^{-1}$ swimming in tail-first and arms-first orientations. Three types of jet propulsion efficiencies were calculated: (i) Froude propulsion efficiency $\left(\eta_{F}\right)$, (ii) rocket motor propulsion efficiency $\left(\eta_{\mathrm{r}}\right)$ and (iii) whole-cycle propulsion efficiency $\left(\eta_{w c}\right)$ (Vogel, 1994; Anderson and DeMont, 2000). The equations used are listed below.

$$
\begin{gathered}
\eta_{\mathrm{F}}=2 U /\left(U_{\mathrm{j}}+U\right), \\
\eta_{\mathrm{r}}=\frac{\left(2 U U_{\mathrm{j}}\right)}{\left(U^{2}+U_{\mathrm{j}}^{2}\right)}, \\
\eta_{\mathrm{wc}}=\frac{\left(2 U U_{\mathrm{j}}\right)}{\left(2 U_{\mathrm{r}} U+3 U^{2}+U_{\mathrm{j}}^{2}\right)},
\end{gathered}
$$

where $U$ is the free-stream swimming velocity, $U_{\mathrm{j}}$ is the horizontal component of the velocity of water expelled from the funnel and $U_{\mathrm{r}}$ is the velocity of water entering the mantle during refilling. $U_{\mathrm{j}}$ was determined from tracking particles ejected from the funnel, while $U_{\mathrm{r}}$ was assumed to be equal to the swimming velocity of the squid.

Flow visualization studies of broad-scale characteristics of the jet wake were also performed. Two squid (mean $D M L=4.2 \mathrm{~cm}$ ) were anesthetized in an isotonic solution of $\mathrm{MgCl}_{2}\left(7.5 \% \mathrm{MgCl}_{2} \cdot 6 \mathrm{H}_{2} \mathrm{O}\right)$ and sea water (Messenger et al., 1985). A $1.5 \mathrm{~mm}$ diameter hole was subsequently bored into the lateral mantle wall using a hypodermic needle, and $3.0 \mathrm{~m}$ of Tygon tubing (1.5 mm outer diameter) was threaded through the hole. A small bead of silicone placed at one end of the tubing prevented dislodgment from the mantle wall. After surgery, each squid was placed in a 378.51 aquarium filled with aerated sea water and allowed to recover. After recovery, dye (food coloring or fluorescene) or milk was pumped slowly into the mantle cavity using a peristaltic pump, and plumes of dye were subsequently expelled from the squid during jetting. Footage of the dye released from the funnel was recorded using Hi-8 video.

Since squid swim at various angles of attack relative to freestream flow, it was of interest to determine the angles at which flow separation occurs. Therefore, a plaster-of-Paris cast of the body (mantle, fins and head) and third (III) pair of arms was constructed from a $6.5 \mathrm{~cm} D M L L$. brevis. A conical, lessdetailed cast of the remaining arm assemblage was also made. Aquasil impression material (Dentsply International Inc., Milford, DE, USA) was poured into the molds and allowed to dry. The final model consisted of a main body and fins attached via embedded wire to the third arm pair and the conical section, which represented the remaining arms. The arms were connected using embedded wire to allow for independent manipulation from the main body. The model was made with the fins fully extended rather than flush against the body because the fins were active over most of the speed range.

The model was attached ventrally to a support stand and placed in a recirculating water tunnel, which had a $31 \mathrm{~cm} \times 40 \mathrm{~cm} \times 240 \mathrm{~cm}$ working section, located at the NASA Langley Research Center (LaRC), Hampton, Virginia. The model was oriented both tail-first and arms-first, and the mantle and arms were positioned independently at various angles of attack $\left(0-50^{\circ}\right)$ relative to free-stream flow. At the anteriormost stagnation point, dye was injected into the water using a NASA dye-injection system, and flow patterns were videotaped using Hi-8 video.

\section{Force measurements}

The model was attached to a force beam containing strain gauges positioned to measure forces parallel (drag) and perpendicular (lift) to free-stream flow. Signals from the strain gauges were amplified using an Omega DMD-465WB strain gauge amplifier, and flow velocity, which was measured simultaneously with force measurements, was recorded using the serial output of the Son-Tek ADV. The models were oriented tail-first and arms-first in the direction of free-stream flow, and the arms and mantle were positioned at various combinations of angle of attack that were representative of behavior videotaped previously. Generally, angles of attack varied from 0 to $50^{\circ}$, and the angle of attack of the leading body section, whether it was the mantle or arms, rarely exceeded the angle of attack of the trailing body section. To reduce the number of arm/mantle combinations, the arms and mantle were positioned in $10^{\circ}$ increments. Drag and lift measurements were performed in the water tunnel at NASA LaRC at four flow velocities $\left(6,12,18\right.$ and $\left.24 \mathrm{~cm} \mathrm{~s}^{-1}\right)$ for each combination of orientation (arms-first or tail-first), arm angle $\left(0-50^{\circ}\right)$ and mantle angle $\left(0-50^{\circ}\right)$.

Acceleration reaction measurements were performed using the same model placed in the Gloucester Point flume, which was smaller but capable of generating higher accelerations than the NASA LaRC tunnel. For these experiments, the model was again oriented tail-first or arms-first relative to free-stream flow, and the arms and mantle were positioned at various representative angle combinations (the arms and mantle were 
positioned in $10^{\circ}$ increments). Forces parallel to free-stream flow and velocity measurements were recorded using the forcebeam arrangement described above and the Son-Tek ADV, respectively, as flow speed was elevated rapidly from 0 to approximately $45-70 \mathrm{~cm} \mathrm{~s}^{-1}$. Four separate trials were performed for each orientation and mantle/arm angle combination.

Data acquisition for all force measurements was accomplished using LabVIEW software (National Instruments), a 16-bit analog-to-digital converter (National Instruments) and an Apple Macintosh G3 computer. Using a LabVIEW Virtual Instrument (VI) developed by the authors, force and velocity measurements were recorded simultaneously to a file at a scan rate of $250 \mathrm{~Hz}$ for $10 \mathrm{~s}$ for each combination of variables (i.e. orientation, mantle angle, arm angle and trial/speed). For acceleration reaction measurements, accelerations $2 \mathrm{~s}$ after flow was increased from rest were computed from velocity measurements. Accelerations in the flow tank ranged from 22 to $34 \mathrm{~cm} \mathrm{~s}^{-2}$, which is similar to peak accelerations reached by free-swimming squid at speeds of $15 \mathrm{~cm} \mathrm{~s}^{-1}$ or below. At speeds above $15 \mathrm{~cm} \mathrm{~s}^{-1}$, free-swimming squid reach much higher accelerations (e.g. $120 \mathrm{~cm} \mathrm{~s}^{-2}$ ), but these accelerations could not be re-created in our water tunnels.

Within the LabVIEW VI, drag, lift and added mass coefficients were calculated continuously during the experiments using two equations. The equation used for drag coefficient $\left(C_{\mathrm{D}}\right)$ and lift $\left(C_{\mathrm{D}}\right)$ coefficient calculations was as follows:

$$
C_{\mathrm{D}} \text { or } C_{\mathrm{L}}=2 F /\left(\rho_{\mathrm{w}} S_{\mathrm{w}} U^{2}\right),
$$

where $F$ is the force parallel to free-stream flow (for drag calculations) or perpendicular to free-stream flow (for lift calculations), $\rho_{\mathrm{w}}$ is the density of fresh water at $22^{\circ} \mathrm{C}$ $\left(998 \mathrm{~kg} \mathrm{~m}^{-3}\right), S_{\mathrm{w}}$ is the wetted surface area of the model and $U$ is the free-stream velocity. The wetted surface area of the models $\left( \pm 0.1 \mathrm{~cm}^{2}\right)$ was determined by covering the model with aluminum foil, cutting the foil so that it lay flat on a piece of paper, tracing the outline of the foil, cutting the tracing out, weighing it and comparing its mass with that of paper of known area. Mean drag and lift coefficients were calculated for each mantle/arm angle combination at each swimming orientation.

Since the model was stationary and the fluid around the model was accelerating during acceleration reaction trials, the following equation was used to calculate the added mass coefficient (Denny, 1993):

$$
C_{\mathrm{A}}=\left[\left(F_{1}-F_{2}\right) /\left(\rho_{w} V_{1} a_{1}\right)-1\right],
$$

where $C_{\mathrm{A}}$ is the added mass coefficient, $F_{1}$ is the instantaneous force acting parallel to free-stream flow recorded $2 \mathrm{~s}$ after flow was accelerated from rest, $F_{2}$ is the force acting parallel to freestream flow under steady-state flow conditions at the velocity recorded $2 \mathrm{~s}$ after flow was accelerated from rest, $\rho_{\mathrm{w}}$ is the density of fresh water at $22{ }^{\circ} \mathrm{C}\left(998 \mathrm{~kg} \mathrm{~m}^{-3}\right), V_{1}$ is the volume of the model and $a_{1}$ is the acceleration of the water relative to the model $2 \mathrm{~s}$ after flow was accelerated from rest. $F_{2}$ was calculated by inserting $C_{\mathrm{D}}$ computed above for the appropriate mantle/arm angle combination into the steady-state drag equation ( $\operatorname{drag}=\frac{1}{2} C_{\mathrm{D}} \rho_{\mathrm{w}} S_{\mathrm{w}} U^{2}$ ), where $U$ is flow velocity $2 \mathrm{~s}$ after acceleration from rest. Mean added mass coefficients were calculated for each mantle/arm angle combination at each of the two swimming orientations.

To provide an estimate of the effects of the fins on drag and lift forces, additional force experiments were conducted in a water tunnel (working section $61 \mathrm{~cm} \times 45.7 \mathrm{~cm} \times 244 \mathrm{~cm}$ ) at the California Institute of Technology, Pasadena, CA, USA. Experiments were performed using the model described above positioned at similar angles of attack and exposed to similar flow velocities. For one set of experiments, the model with attached fins was used; for a second set of experiments, the model with fins removed was used. Force measurements were collected using three Interface $2.25 \mathrm{~kg}$ strain gauge load cells (Interface, Inc. Scottsdale, AZ, USA) [two load cells measured forces normal to flow (lift), and one load cell measured forces parallel to flow (drag)] connected to a customized force balance (Lisoski, 1993). Output from the load cells was amplified using three Interface SGA amplifiers/conditioners and was recorded using a Dash 8 series data recorder (AstroMed, Inc.). Data were collected at $200 \mathrm{~Hz}$ for $10 \mathrm{~s}$.

\section{Hydrodynamics}

Using the coefficients computed from force measurements described above, instantaneous drag, lift and acceleration reaction forces were calculated on a frame-by-frame basis for three squid swimming at speeds ranging from $3-24 \mathrm{~cm} \mathrm{~s}^{-1}$. The three squid, which were $1.8,4.4$ and $7.6 \mathrm{~cm}$ in $D M L$, were selected (i) because they were representative of the size range considered in this study, (ii) because they were particularly cooperative and (iii) because they swam in both orientations (tail-first and arms-first) for many speeds at or below $12 \mathrm{~cm} \mathrm{~s}^{-1}$. For each digitized frame, the steady components of drag $(D)$ and lift $(L)$ were calculated using the equations:

$$
\begin{aligned}
& D=\frac{1}{2} C_{\mathrm{D}} \rho_{\mathrm{w}} S_{\mathrm{w}} U^{2}, \\
& L=\frac{1}{2} C_{\mathrm{L}} \rho_{\mathrm{w}} S_{\mathrm{w}} U^{2} .
\end{aligned}
$$

Drag and lift coefficients measured from the models were used for these equations. Since coefficients derived from the models were measured at $10^{\circ}$ intervals, mantle and arm angles recorded in the video frames were rounded to the nearest $10^{\circ}$ and assigned appropriate coefficients. For speeds at which the fins were employed, drag and lift coefficients measured from models with extended fins were used, whereas for speeds at which the fins were not employed, drag and lift coefficients measured from models without fins were used. A seawater density of $1023 \mathrm{~kg} \mathrm{~m}^{-3}$ was used for $\rho_{\mathrm{w}}$. For wetted surface area $\left(S_{\mathrm{w}}\right)$ calculations, the head and arms of each squid were treated as a right cone with height equal to the distance from the head to the tip of the third (III) arm pair and radius equal to the mean of the dorsal and lateral head radii. The surface area of the cone was $\pi r s$, where $r$ was the mean radius and $s$ was the hypotenuse of the mean radius and height. For wetted surface area calculations $\left( \pm 0.1 \mathrm{~cm}^{2}\right)$ of the remainder of the body, the mantle and fins were cut, placed flat on a sheet of paper and 
traced. The paper was cut out, weighed and compared with the mass of paper of known area. In addition to calculating drag and lift values for each digitized frame, mean drag and mean lift values for each video sequence were computed.

Because the squid were accelerating within the flume, the following equation was used to compute the acceleration reaction $\left(R_{\mathrm{A}}\right)$ (Denny, 1993):

$$
R_{\mathrm{A}}=m a_{2}+C_{\mathrm{A}} \rho_{\mathrm{w}} V_{2} a_{2} .
$$

The term $m$ is the instantaneous mass of the squid $(\mathrm{kg})$, which was the mass of the squid without water in its mantle cavity plus the mass of water in the mantle cavity (see jet thrust calculations for mantle water volume determinations). The term $a_{2}$ is the instantaneous acceleration of the squid, $C_{\mathrm{A}}$ is the added mass coefficient for the appropriate mantle/arm angles and $\rho_{\mathrm{w}}$ is the density of sea water. The term $V_{2}$ is instantaneous volume, which was the volume of the fins, arms and head plus the external volume of the mantle throughout the jetting period (see jet thrust calculations for external mantle volume determinations). As was the case for drag and lift measurements, mantle and arm angles were rounded to the nearest $10^{\circ}$ for simplicity, and the appropriate added mass coefficients were used in frame calculations. In addition to the instantaneous acceleration reaction computed for each digitized frame, an overall mean acceleration reaction for each video sequence was calculated.

During the contraction phase of the jet cycle, water is forcibly ejected from the mantle cavity through the funnel to generate thrust. Jet thrust $\left(T_{\mathrm{j}}\right)$ may be calculated using the equation (Daniel, 1983; O’Dor, 1988):

$$
T_{\mathrm{j}}=U_{\mathrm{j}} \rho_{\mathrm{w}}\left(V_{\mathrm{w}} / t\right),
$$

where $U_{\mathrm{j}}$ is the velocity of water expelled from the funnel, $\rho_{\mathrm{w}}$ is the density of sea water $\left(1023 \mathrm{~kg} \mathrm{~m}^{-3}\right)$ and $V_{\mathrm{w}}$ is the volume of water expelled over time $(t)$. $U_{\mathrm{j}}$ was determined using the flow visualization studies described above and was considered to be constant throughout the contraction phase of the jet cycle. O'Dor (O'Dor, 1988) determined that changes in jet velocity during the jet cycle are negligible, contributing only $0.5-1.0 \%$ of the total jet thrust over the speed range. Thus, an assumption of a constant $U_{\mathrm{j}}$ should not lead to significant errors in thrust calculations. To determine the volume of expelled water $\left(V_{\mathrm{w}}\right)$, mantle outlines visible in frames of lateral video footage were divided into a series of cylinders and a cone, which represented the posterior tip of the mantle, using the Peak Motus motion system. Division of the mantle into a series of cylinders and a cone was accomplished by sectioning the mantle of the three squid into a series of equally spaced segments over several jet cycles. The distance between adjacent segments was considered to be the height of a given cylinder or cone; heights varied from 0.20 to $0.60 \mathrm{~cm}$ depending on the size of the squid. The radius of each cylinder was simply half the mean of the two segments forming the cylinder; the radius of the cone was half the segment forming the cone base. (Given that differences in mantle diameter viewed aerially and laterally were negligible, uniform circumferential expansion of the mantle was assumed.) A linear regression of the volumetric sum of the cylinders and cone (computed in each video frame throughout several jet cycles) on mantle diameter (measured at a point $60 \%$ of the mantle length from the tail in each video frame throughout the jet cycles) was performed. This regression equation allowed the external volume to be predicted from mantle diameter. For each frame of video, subtracting the volume of the mantle tissue (without fins) and internal viscera from the external volume determined the volume of water within the mantle. The volume of expelled water per time $\left(V_{\mathrm{w}} / t\right)$ was simply the difference in internal mantle water volume between frames divided by the frame rate.

Since the funnel was oriented at various angles relative to free-stream flow throughout the jet cycle, jet thrust was divided into horizontal and vertical components using the equations:

$$
\begin{aligned}
T_{\mathrm{j}(\mathrm{h})} & =T_{\mathrm{j}} \cos \beta, \\
T_{\mathrm{j}(\mathrm{v})} & =T_{\mathrm{j}} \sin \beta,
\end{aligned}
$$

where $\beta$ is funnel angle. Over a video sequence, the vertical force components should equal the buoyant weight of the squid if altitude is maintained. On the basis of weight measurements made in air and water, the water/air weight ratio was $0.034 \pm 0.012$ (mean \pm S.D., $N=12$ ) for $L$. brevis, which is remarkably similar to the water/air weight ratio of 0.033 measured for Loligo opalescens (O'Dor, 1988). Given this ratio, buoyant weight $(B)$ is $0.034 \mathrm{mg}$, where $m$ is the mass of the squid $(\mathrm{kg})$ and $\boldsymbol{g}$ is the acceleration of gravity $\left(9.81 \mathrm{~m} \mathrm{~s}^{-2}\right)$. Although squid did not begin and end video sequences at the same altitude, as was the case for horizontal position, vertical altitude did not differ dramatically at the beginning and end of video sequences (see Table 4). Therefore, the following equation is a reasonable predictor of the balance of vertical forces at the end of the video sequence:

$$
B=T_{\mathrm{j}(\mathrm{v})}+T_{\mathrm{f}(\mathrm{v})}+L,
$$

where $B$ is buoyant weight, $T_{\mathrm{j}(\mathrm{v})}$ is mean vertical jet thrust, $T_{\mathrm{f}(\mathrm{v})}$ is mean vertical fin thrust and $L$ is mean lift over the video sequence. Two values of lift were considered in the above equation: (i) the lift of the body with extended fins and (ii) the lift of the body without fins. This was carried out to predict the total lift (passive and active) generated by the fins. Direct fin thrust measurements, like wing thrust measurements, are complex and require high-resolution flow visualization of wake structure (Rayner, 1979; Blake, 1983a; Blake, 1983b; Ellington, 1984; Spedding et al., 1984; Dickinson and Götz, 1996; Drucker and Lauder, 1999), precise force measurements of the oscillating appendage (Dickinson and Götz, 1996; Lehmann and Dickinson, 1997) and/or three-dimensional kinematic footage (Lauder and Jayne, 1996; Westneat, 1996). These procedures were beyond the scope and resources of this project. However, given that $B, T_{\mathrm{j}(\mathrm{v})}$ and $L$ were known, the mean vertical fin thrust $\left(T_{\mathrm{j}(\mathrm{v})}\right)$ over the video sequence could be estimated using equation 13 .

The horizontal thrust forces should be equal to the horizontal resistive forces if there is no acceleration or deceleration. 


\section{Swimming mechanics and behaviour of Lolliguncula brevis 3661}

Therefore, at the end of each video sequence when there was no net velocity change:

$$
T_{\mathrm{j}(\mathrm{h})}+T_{\mathrm{f}(\mathrm{h})}=F_{\mathrm{r}}+D+R_{\mathrm{A}}
$$

where $T_{\mathrm{j}(\mathrm{h})}$ is mean horizontal jet thrust, $T_{\mathrm{f}(\mathrm{h})}$ is mean horizontal fin thrust, $F_{\mathrm{r}}$ is the mean refilling force, $D$ is mean drag and $R_{\mathrm{A}}$ is the mean acceleration reaction over the video sequence. The refilling force $\left(F_{\mathrm{r}}\right)$ is $F_{\mathrm{r}}=\rho_{\mathrm{w}}\left(V_{\mathrm{v}} / t\right) U_{\mathrm{i}}$, where $\rho_{\mathrm{w}}$ is the density of sea water, $V_{\mathrm{v}} / t$ is the amount of water entering the mantle over time $(t)$ and $U_{\mathrm{i}}$ is intake water velocity (intake water velocity was assumed to be equal to the swimming velocity of the squid). Mean horizontal fin thrust $\left(T_{\mathrm{f}(\mathrm{h}}\right)$ over video sequences was calculated using equation 14 and the above variables.

\section{Results}

Critical and transition swimming speeds

Mean critical swimming speeds $\left(U_{\text {crit }}\right)$ for the four size classes ranged from $15.3 \pm 5.3$ to $22.8 \pm 5.6 \mathrm{~cm} \mathrm{~s}^{-1}$ (means \pm S.D., $N=6-10$ ); however, certain squid were capable of sustaining much higher swimming velocities (Table 1). The majority of squid swam in an arms-first orientation upon initial placement into swim tunnels. Many squid continued to swim in an armsfirst orientation or alternated between arms-first and tail-first swimming at low speeds before switching exclusively to tailfirst swimming at some higher speed. Mean transition speeds $\left(U_{\mathrm{t}}\right)$, i.e. speeds above which squid swam exclusively in a tailfirst orientation, for those squid that swam in both orientations ranged from 9.0 to $15.3 \pm 2.7 \mathrm{~cm} \mathrm{~s}^{-1}$ (means \pm S.D., $N=2-7$ ) (Table 1).

\section{Kinematic measurements}

During tail-first swimming, angles of attack of the mantle, arms and funnel decreased with increasing speed for squid in all four size classes (linear regressions $P<0.05$; Fig. 1, Fig. 2). Over the speed range considered in this study, angles of attack during tail-first swimming differed significantly according to body section (i.e. mantle, arms and funnel) and size class (twofactor ANOVA: body section, d.f. $=2,75, F=14.99, P<0.0001$; size class, d.f. $=3,75, \quad F=6.59, \quad P=0.0005)$. Subsequent $a$ posteriori Student-Newman-Keuls (SNK) tests revealed that the funnel was oriented at the greatest angle of attack, the arms were positioned at a higher angle of attack than the mantle (see Fig. 2) and squid $3.0-4.9 \mathrm{~cm}$ in $D M L$ had the lowest overall angles of attack. Moreover, in the tail-first swimming mode, the angle of attack of the arms often increased briefly during mantle expansion (refilling) (Fig. 3).

Because of limited data, significant declines in angles of attack with speed during arms-first swimming were not always detected for all size classes. However, a clear declining trend in angle of attack of most of the body sections with increasing speed was apparent in squid of 1.0-2.9 and 3.0-4.9 cm DML, while significant declines in angles of attack with increasing speed were detected for squid of 5.0-6.9 and 7.0-8.9 cm DML (Fig. 1). Angles of attack during arms-first swimming differed according to body section but not according to size class (twofactor ANOVA: body section, d.f.=2,33, $F=124.85, P<0.0001$; size class, d.f. $=3,33, F=2.03, P=0.1294)$. SNK tests revealed that, during arms-first swimming, funnel angles were greatest over the entire speed range and mantle angles of attack were greater than arm angles of attack (Fig. 2).

To assess whether there were significant differences in angles of attack between tail-first and arms-first swimming modes, a two-factor (body section and orientation) ANOVA was performed on data pooled by size class. (Only those speeds at which both tail-first and arms-first swimming were employed were considered.) A significant interaction between body section and orientation was detected (two-factor ANOVA: body section $\times$ orientation, d.f. $=2,78 ; \quad F=31.602$; $P<0.0001)$. Subsequent SNK tests performed to decouple the interaction revealed that there was no significant difference between mantle angles of attack during arms-first and tail-first swimming, but that the angle of attack of the funnel was greater during arms-first swimming and that the angle of attack of the arms was greater during tail-first swimming.

Mantle contraction rates for squid $1.0-2.9 \mathrm{~cm}$ in $D M L$ swimming in the tail-first swimming mode increased from $2.4 \pm 0.6$ contractions $\mathrm{s}^{-1}$ at $3 \mathrm{~cm} \mathrm{~s}^{-1}$ to $4.1 \pm 0.9$ contractions s $\mathrm{s}^{-1}$ at $18 \mathrm{~cm} \mathrm{~s}^{-1}$ (means \pm S.D., $N=3$ ) (Fig. 4). However, contraction

Table 1. Mean critical swimming speeds and ranges and mean transition speeds and ranges for four size classes of Lolliguncula brevis

\begin{tabular}{lccccrr}
\hline $\begin{array}{l}\text { Size class } \\
(\mathrm{cm} D M L)\end{array}$ & $N_{\text {crit }}$ & $\begin{array}{c}U_{\text {crit mean }} \\
\left(\mathrm{cm} \mathrm{s}^{-1}\right)\end{array}$ & $\begin{array}{c}U_{\text {crit range }} \\
\left(\mathrm{cm} \mathrm{s}^{-1}\right)\end{array}$ & $N_{\mathrm{t}}$ & $\begin{array}{r}U_{\mathrm{t} \text { mean }} \\
\left(\mathrm{cm} \mathrm{s}^{-1}\right)\end{array}$ & $\begin{array}{r}U_{\mathrm{t} \text { range }} \\
\left(\mathrm{cm} \mathrm{s}^{-1}\right)\end{array}$ \\
\hline $1.0-2.9$ & 8 & $15.3 \pm 5.3$ & $11.9-24.1$ & 2 & 9.0 & 9.0 \\
$3.0-4.9$ & 10 & $22.8 \pm 5.6$ & $14.8-32.4$ & 7 & $10.5 \pm 1.8$ & $8.0-12.0$ \\
$5.0-6.9$ & 8 & $20.5 \pm 3.5$ & $15.0-25.5$ & 5 & $12.6 \pm 2.5$ & $9.0-15.0$ \\
$7.0-8.9$ & 6 & $22.2 \pm 5.3$ & $18.1-33.7$ & 4 & $15.3 \pm 2.7$ & $12.0-18.0$
\end{tabular}

The critical swimming speed $\left(U_{\text {crit }}\right)$ is the maximum velocity squid can sustain for 15 min, whereas the transition speed $\left(U_{\mathrm{t}}\right)$ is the speed at and above which squid swim exclusively in a tail-first orientation.

The number of squid considered in critical speed $\left(N_{\text {crit }}\right)$ and transition speed $\left(N_{\mathrm{t}}\right)$ calculations also are listed.

All error terms represent \pm 1 S.D.

$D M L$, dorsal mantle length. 
Tail-first


Arms-first
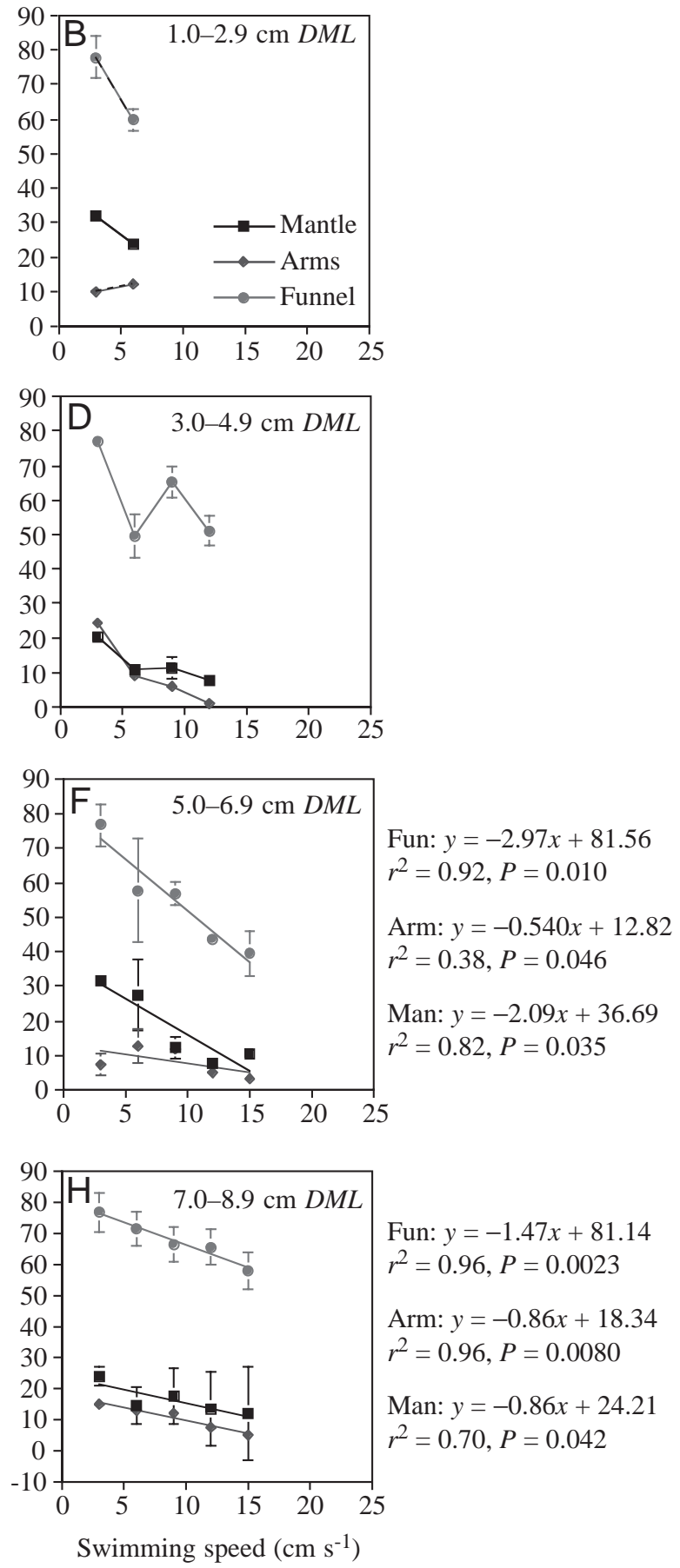

Fig. 1. Mantle (Man), arm and funnel (Fun) angles of attack for Lolliguncula brevis swimming at various speeds. Results for squid swimming in a tail-first orientation are displayed in A, C, E and G, whereas those for squid swimming in an arms-first orientation are shown in B, D, F and H. Data from four size classes are included in the figure. Squid 1.0-2.9 cm in dorsal mantle length $(D M L)$ are depicted in A and B, squid $3.0-4.9 \mathrm{~cm}$ in $D M L$ are depicted in $\mathrm{C}$ and $\mathrm{D}$, squid $5.0-6.9 \mathrm{~cm}$ in $D M L$ are depicted in $\mathrm{E}$ and $\mathrm{F}$ and squid $7.0-8.9 \mathrm{~cm}$ in $D M L$ are depicted in $\mathrm{G}$ and $\mathrm{H}$. When a significant linear relationship between angle of attack and speed was detected, regression lines were plotted, and regression equations, $r^{2}$ values and $P$ values were included to the right of graphs. When significant relationships were not detected, the data points were simply connected with lines and no regression information was included. All error bars represent \pm 1 S.E.M. $(N=3)$.

rates for squid belonging to larger size classes did not increase significantly with swimming speed (range $1.6 \pm 0.2$ to $2.2 \pm 0.5$ contractions s $^{-1}$ ) (means \pm S.D., $N=3$ ) (Fig. 4). Not surprisingly, mean mantle contraction rate over the speed range differed according to size class [one-factor (size class) ANOVA: d.f. $=3,25 ; F=12.726 ; P<0.0001]$; contraction rates 
Tail-first

Fig. 2. Video frames of a $4.4 \mathrm{~cm}$ dorsal mantle length Lolliguncula brevis swimming tail-first at 3 and $24 \mathrm{~cm} \mathrm{~s}^{-1}$ (upper frames) and arms-first at 3 and $12 \mathrm{~cm} \mathrm{~s}^{-1}$ (lower frames). Mantle and arm angles of attack decrease with increasing swimming speed for both swimming orientations. Angle of attack differences are less pronounced for arms-first swimming because a more restricted velocity range is considered (L. brevis only swims arms-first at low to intermediate speeds). Note that the trailing body section, whether the arms during tail-first swimming or the mantle during arms-first swimming, is often positioned at higher angles of attack than the leading body section.

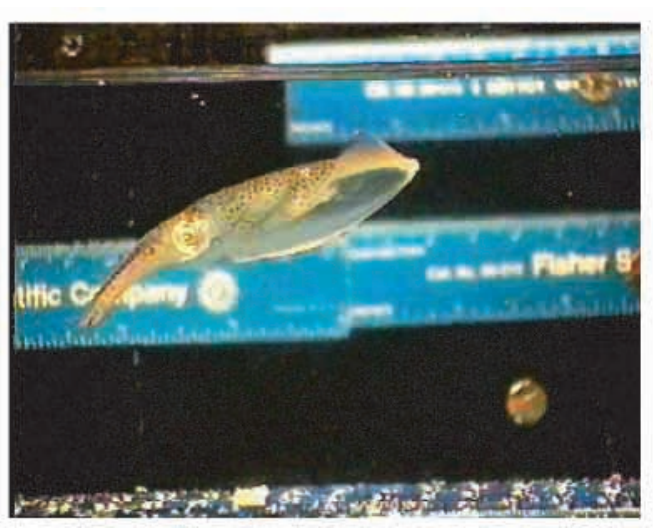

$3 \mathrm{~cm} \mathrm{~s}^{-1}$

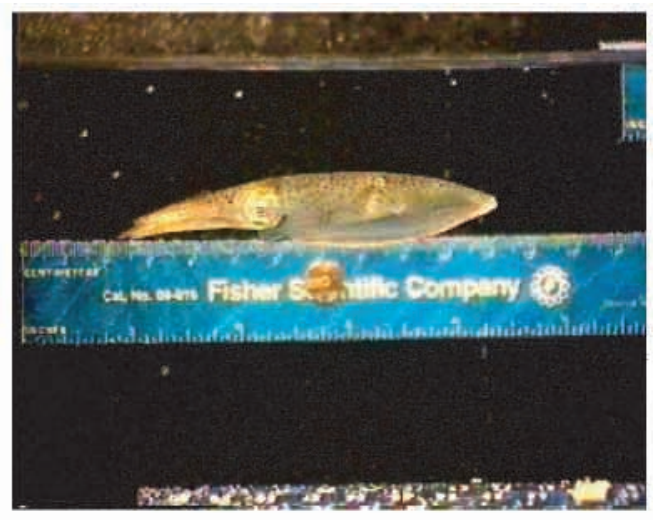

$24 \mathrm{~cm} \mathrm{~s}^{-1}$

Arms-first

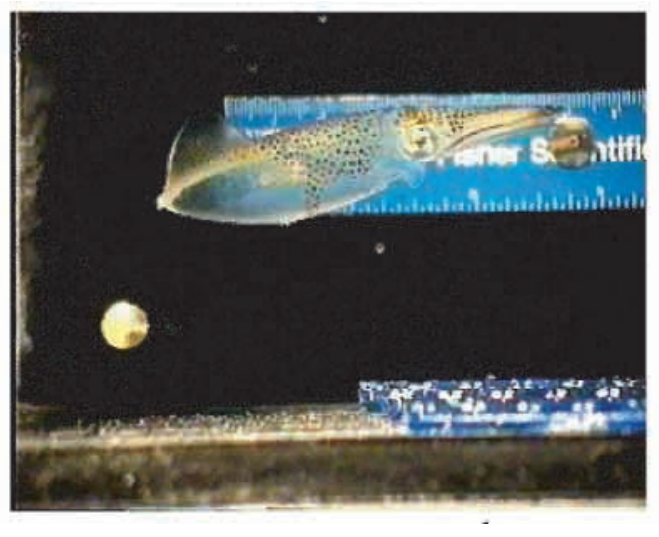

$3 \mathrm{~cm} \mathrm{~s}^{-1}$

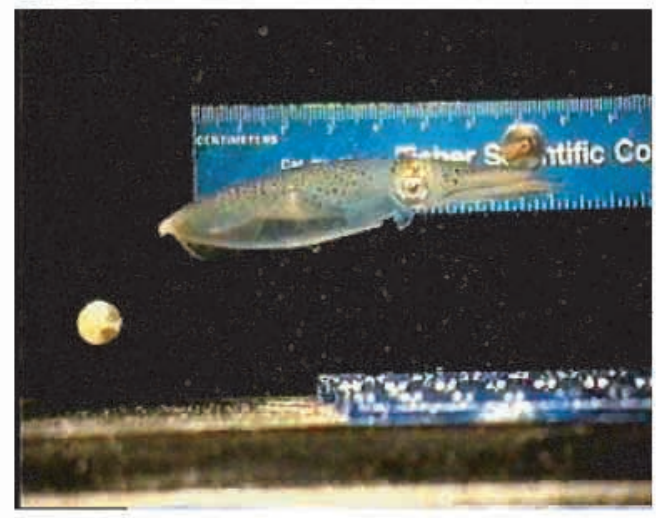

$12 \mathrm{~cm} \mathrm{~s}^{-1}$ for squid $1.0-2.9 \mathrm{~cm}$ in $D M L$ were greater than those in the other size classes, and no significant differences were detected among squid in the larger size classes $(3 \mathrm{~cm}$ or more in $D M L)$.

While swimming arms-first, no clear increase in mantle contraction rate with speed was apparent (Fig. 4). On the basis of a one-factor (size class) ANOVA (d.f.=3,10; $F=21.381$; $P<0.0001)$ performed over the speed range and subsequent $a$ posteriori SNK tests, contraction rates for squid $7.0-8.9 \mathrm{~cm}$ in $D M L$ were lowest, and squid $5.0-6.9 \mathrm{~cm}$ in $D M L$ had lower contraction rates than squid $3.0-4.9 \mathrm{~cm}$ in $D M L$.

When data were pooled by size class, mantle contraction frequency was found to be greater during tail-first swimming than during arms-first swimming [one-factor ANOVA (orientation): d.f.=1,26; $F=6.536 ; P<0.0168$ ]. (Again only speeds at which both swimming orientations were used were considered.) During mantle contractions, funnel diameter frequently increased during the initial portion of the contraction but then decreased gradually throughout the remainder of the contraction and even into mantle refilling (expansion) (Fig. 5).

For squid $3.0-4.9 \mathrm{~cm}, 5.0-6.9 \mathrm{~cm}$ and $7.0-8.9 \mathrm{~cm}$ in $D M L$, swimming tail-first, fin activity decreased significantly with swimming velocity until a velocity was reached at which the fins simply remained wrapped around the mantle (Fig. 4). Although a significant linear decline in fin-beat frequencies with speed was not detected for squid $1.0-2.9 \mathrm{~cm}$ in $D M L$, a clear decreasing trend in fin use with speed was apparent (Fig. 4). No significant difference in fin-beat frequency over the speed range was detected between the size classes [one-factor (size class) ANOVA: d.f. $=3,19 ; \quad F=0.072$; $P=0.9744]$.

Squid used fin motion for all speeds at which arms-first swimming was employed, and no linear decrease in fin use with speed was detected (Fig. 4). During arms-first swimming, squid belonging to the two smaller size classes $(1.0-2.9 \mathrm{~cm}$ and $3.0-4.9 \mathrm{~cm} D M L$ ) had greater fin-beat frequencies than squid belonging to the largest size class $(7.0-8.9 \mathrm{~cm} D M L)$ over the speed range considered [one-factor ANOVA (size class): d.f.=3,11; $F=12.36 ; P=0.0008$ ].

When data for speeds at which both swimming orientations were used were pooled by size class, fin-beat frequencies were higher during arms-first swimming than during tail-first swimming [one-factor ANOVA (orientation): d.f.=1,26; $F=46.39 ; \quad P<0.0001]$ (Fig. 4). At low speeds $\left(6 \mathrm{~cm} \mathrm{~s}^{-1}\right.$ or below) during tail-first swimming and at all speeds during arms-first swimming, fin downstrokes often occurred during 
mantle contraction and refilling (Fig. 3, Fig. 5B), whereas at higher speeds when fin activity was reduced, fin downstrokes frequently occurred during mantle contractions (Fig. 5A).

Although contraction rates during tail-first swimming did not increase significantly with speed for squid in the size classes $3.0-4.9 \mathrm{~cm}$, $5.0-6.9 \mathrm{~cm}$ and $7.0-8.9 \mathrm{~cm}$ DML, mantle expansion did increase with speed (linear regressions, $P<0.05$; Fig. 6). However, no clear increase in mantle expansion with speed was detected for squid $1.0-2.9 \mathrm{~cm}$ in $D M L$, the size class in which mantle contraction did increase with swimming speed. Mantle expansion of squid swimming in an arms-first orientation did not increase significantly with speed (Fig. 6). During tail-first swimming, vertical fin motion (the absolute vertical distance between maximum upstroke and maximum downstroke) decreased with increasing swimming velocity (linear regressions, $P<0.05$ ), but no detectable decrease in fin amplitude was found for armsfirst swimming (Fig. 6).

The time required for mantle expansion during tail-first swimming was greater than that required to contract the mantle for squid in size classes $3.0-4.9 \mathrm{~cm}, 5.0-6.9 \mathrm{~cm}$ and $7.0-8.9 \mathrm{~cm}$ $D M L$ over the range of speeds considered (paired $t$-test, $P<0.05$ ) (Table 2 ). When data from all the size classes were pooled, this difference was highly significant $(P=0.0002)$. When swimming in an arms-first orientation, only squid $3.0-4.9 \mathrm{~cm}$ in $D M L$ had greater mantle expansion than contraction times, but mantle expansion times were significantly greater than contraction times when data from all the size classes were pooled $(P=0.0064)$ (Table 2). Mantle expansion time decreased with increased swimming speed only for squid $1.0-2.9 \mathrm{~cm}$ in $D M L$ while swimming tail-first (linear regression, $\quad P=0.0080 ; \quad r^{2}=0.857$ ) (Table 2). Mantle contraction time decreased with increasing swimming speed for squid $1.0-2.9 \mathrm{~cm}$ and $3.0-4.9 \mathrm{~cm}$ in $D M L$ while swimming tail-first (linear regression, $P=0.0034, \quad r^{2}=0.907$ for $1.0-2.9 \mathrm{~cm} \quad D M L$; $P=0.0391 ; r^{2}=0.535$ for $3.0-4.9 \mathrm{~cm} D M L$ ) (Table 2).

No significant differences between upward and downward fin stroke times were detected, and there was no increase or decrease in upward or downward fin stroke time with increasing speed for squid swimming in either tail-first or arms-first orientations (Table 2). Furthermore, no consistent increase or decrease in trailing edge fin speed with increasing swimming speed was detected when size classes were examined separately; however, when the size classes were pooled, a linear
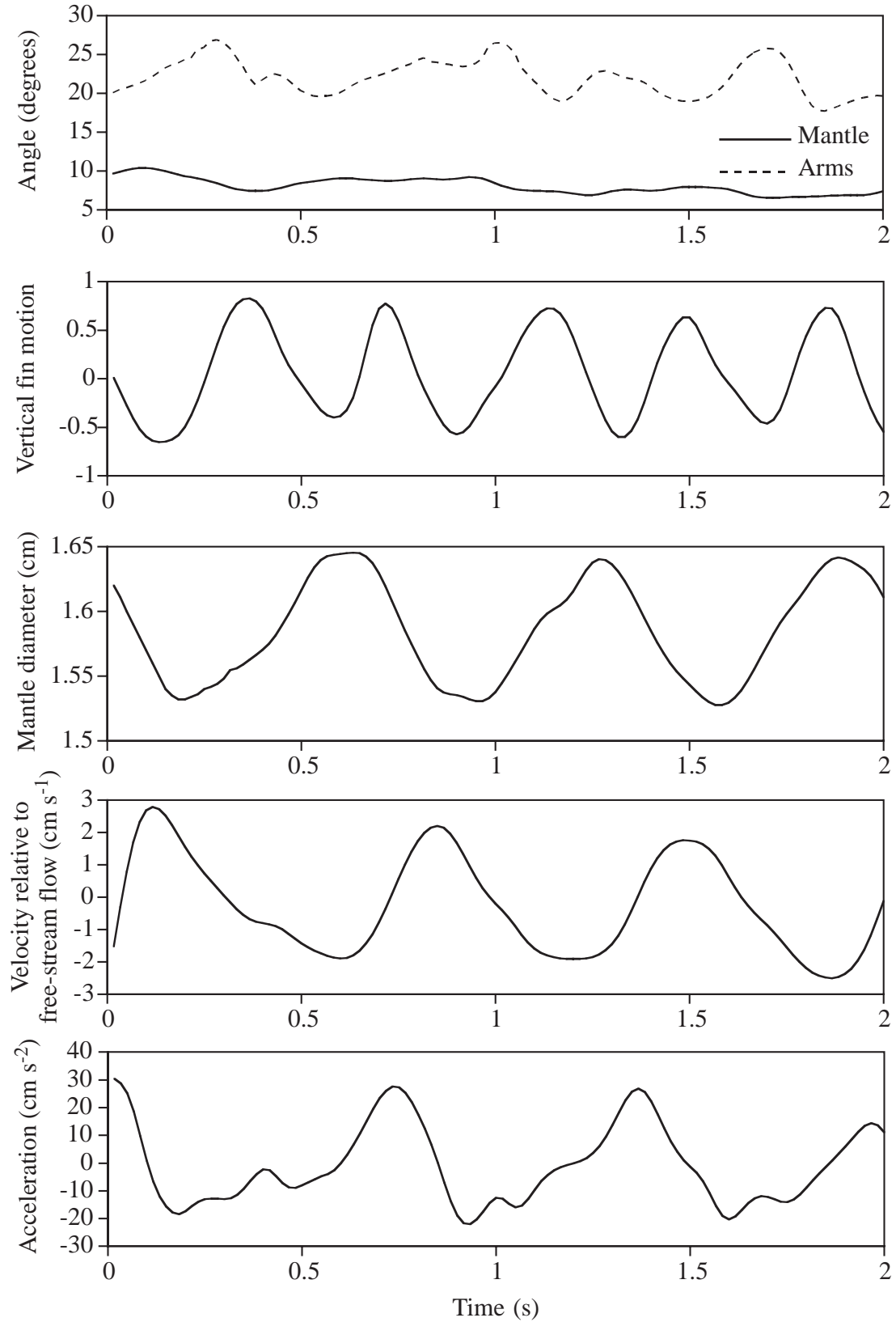

Fig. 3. Arm and mantle angles of attack, vertical fin motion (relative to the point where the fin connects to the mantle), mantle diameter, changes in linear velocity (relative to free-stream flow) and acceleration for a $4.4 \mathrm{~cm}$ dorsal mantle length $(D M L)$ Lolliguncula brevis swimming tail-first at $6 \mathrm{~cm} \mathrm{~s}^{-1}$ against a current in a flume. In total, 60 frames were analyzed to generate the traces.

increase in fin speed with increasing swimming velocity was detected for squid swimming tail-first $\left(P=0.0151 ; r^{2}=0.461\right)$ (Table 2). Mean trailing edge fin speeds ranged from 4.2 to 12.3 $\mathrm{cm} \mathrm{s}^{-1}$. At swimming speeds below $9 \mathrm{~cm} \mathrm{~s}^{-1}$, trailing edge fin speeds generally exceeded swimming speeds, and the trailing edge fin wave resembled a sideways ' $S$ '. At speeds of $9-12 \mathrm{~cm} \mathrm{~s}^{-1}$ or above, trailing edge fin speeds were generally less than swimming speed, and the trailing fin wave more closely resembled an inverted ' $\mathrm{V}$ ', with the distal portion of the wave at an obtuse angle relative to the oncoming water flow. 
Table 2. Summary of results of paired $\mathrm{t}$-tests and linear regressions performed on kinematic data collected from Lolliguncula brevis swimming in tail-first and armsfirst orientations over a range of speeds

\begin{tabular}{|c|c|c|c|c|c|c|c|c|}
\hline $\begin{array}{l}\text { Size class } \\
(\mathrm{cm} D M L)\end{array}$ & Orientation & $\begin{array}{c}\text { Paired } \\
\text { comparison of } \\
\text { mantle expansion } \\
\text { and contraction } \\
\text { times (s) }\end{array}$ & $\begin{array}{l}\text { Paired comparison } \\
\text { of upward and } \\
\text { downward fin } \\
\text { stroke times (s) }\end{array}$ & $\begin{array}{c}\text { Regression } \\
\text { of mantle } \\
\text { expansion and } \\
\text { contraction times } \\
\text { (s) on swimming } \\
\text { speed }\left(\mathrm{cm} \mathrm{s}^{-1}\right)\end{array}$ & $\begin{array}{c}\text { Regression } \\
\text { of upward } \\
\text { and downward } \\
\text { fin stroke times } \\
\text { (s) on swimming } \\
\text { speed }\left(\mathrm{cm} \mathrm{s}^{-1}\right)\end{array}$ & $\begin{array}{c}\text { Regression } \\
\text { of trailing } \\
\text { edge fin speed } \\
\text { (s) on swimming } \\
\text { speed }\left(\mathrm{cm} \mathrm{s}^{-1}\right)\end{array}$ & $\begin{array}{c}\text { Regression } \\
\text { of mean maximum } \\
\text { positive }(+) \text { and } \\
\text { negative }(-) \text { speed } \\
\text { deviations }\left(\mathrm{cm} \mathrm{s}^{-1}\right) \\
\text { on swimming } \\
\text { speed }\left(\mathrm{cm} \mathrm{s}^{-1}\right)\end{array}$ & $\begin{array}{c}\text { Regression of } \\
\text { mean maximum } \\
\text { acceleration }(+) \\
\text { and deceleration }(-) \\
\text { on swimming } \\
\text { speed }\left(\mathrm{cm} \mathrm{s}^{-1}\right)\end{array}$ \\
\hline $1.0-2.9$ & $\mathrm{~T}$ & $P=0.2856$ & $P=0.0694$ & $\begin{array}{l}\mathrm{E}: P=0.0080^{*} ; \\
r^{2}=0.857 ; \mathrm{m}=-0.006 \\
\mathrm{C}: P=0.0034^{*} \\
r^{2}=0.907 ; \mathrm{m}=-0.004\end{array}$ & $\begin{array}{l}\mathrm{U}: P=0.6667 \\
\mathrm{D}: P=0.4065\end{array}$ & $P=0.3111$ & $\begin{array}{l}+: P=0.0824 \\
-: P=0.0133^{*} \\
r^{2}=0.818 ; \mathrm{m}=-0.148\end{array}$ & $\begin{array}{l}+: P<0.0001^{*} \\
r^{2}=0.985 ; \mathrm{m}=3.285 \\
-: P=0.0003^{*} \\
r^{2}=0.974 ; \mathrm{m}=-4.446\end{array}$ \\
\hline $1.0-2.9$ & A & NA & NA & NA & NA & NA & NA & NA \\
\hline $3.0-4.9$ & $\mathrm{~T}$ & $P=0.0095^{*} ; \mathrm{E}>\mathrm{C}$ & $P=0.4274$ & $\begin{array}{l}\mathrm{E}: P=0.2783 \\
\mathrm{C}: P=0.0391 * ; \\
r^{2}=0.535 ; \mathrm{m}=-0.0004\end{array}$ & $\begin{array}{l}\mathrm{U}: P=0.2339 \\
\mathrm{D}: P=0.6143\end{array}$ & $P=0.2833$ & $\begin{array}{l}+: P=0.0087^{*} \\
r^{2}=0.709 ; \mathrm{m}=0.168 \\
-: P=0.0088^{*} \\
r^{2}=0.708 ; \mathrm{m}=-0.165\end{array}$ & $\begin{array}{l}+: P=0.0008 * \\
r^{2}=0.868 ; \mathrm{m}=3.223 \\
-: P=0.7374\end{array}$ \\
\hline $3.0-4.9$ & A & $P=0.0463^{*} ; \mathrm{E}>\mathrm{C}$ & $P=0.3910$ & $\begin{array}{l}\mathrm{E}: P=0.8236 \\
\text { C: } P=0.7418\end{array}$ & $\begin{array}{l}\mathrm{U}: P=0.8790 \\
\mathrm{D}: P=0.9418\end{array}$ & $P=0.1048$ & $\begin{array}{l}+: P=0.3808 \\
-: P=0.9200\end{array}$ & $\begin{array}{l}+: P=0.3660 \\
-: P=0.5479\end{array}$ \\
\hline $5.0-6.9$ & $\mathrm{~T}$ & $P=0.0245^{*} ; \mathrm{E}>\mathrm{C}$ & $P=0.3280$ & $\begin{array}{l}\mathrm{E}: P=0.1126 \\
\mathrm{C}: P=0.3157\end{array}$ & $\begin{array}{l}\mathrm{U}: P=0.4556 \\
\mathrm{D}: P=0.2134\end{array}$ & $P=0.3155$ & $\begin{array}{l}+: P=0.0311^{*} \\
r^{2}=0.612 ; \mathrm{m}=0.193 \\
-: P=0.0439^{*} \\
r^{2}=0.563 ; \mathrm{m}=-0.152\end{array}$ & $\begin{array}{l}+: P<0.0007^{*} \\
r^{2}=0.824 ; \mathrm{m}=2.834 \\
-: P=0.0397 * \\
r^{2}=0.555 ; \mathrm{m}=-2.111\end{array}$ \\
\hline $5.0-6.9$ & A & $P=0.0663$ & $P=0.3325$ & $\begin{array}{l}\mathrm{E}: P=0.8863 \\
\mathrm{C}: P=0.7324\end{array}$ & $\begin{array}{l}\mathrm{U}: P=0.4568 \\
\mathrm{D}: P=0.1838\end{array}$ & $P=0.6143$ & $\begin{array}{l}+: P=0.5447 \\
-: P=0.1156\end{array}$ & $\begin{array}{l}+: P=0.2894 \\
-: P=0.2252\end{array}$ \\
\hline $7.0-8.9$ & $\mathrm{~T}$ & $P=0.0119^{*} ; \mathrm{E}>\mathrm{C}$ & $P=0.3933$ & $\begin{array}{l}E: P=0.3362 \\
C: P=0.4155\end{array}$ & $\begin{array}{l}\mathrm{U}: P=0.7115 \\
\mathrm{D}: P=0.7594\end{array}$ & $P=0.1554$ & $\begin{array}{l}+: P=0.2391 \\
-: P=0.0897\end{array}$ & $\begin{array}{l}+: P=0.0293 * \\
r^{2}=0.575 ; \mathrm{m}=0.745 \\
-: P=0.9235\end{array}$ \\
\hline $7.0-8.9$ & A & $P=0.0814$ & $P=0.2038$ & $\begin{array}{l}\mathrm{E}: P=0.1888 \\
\mathrm{C}: P=0.3437\end{array}$ & $\begin{array}{l}\mathrm{U}: P=0.2116 \\
\mathrm{D}: P=0.2557\end{array}$ & $P=0.7694$ & $\begin{array}{l}+: P=0.1097 \\
-: P=0.0659\end{array}$ & $\begin{array}{l}+: P=0.7270 \\
-: P=0.4159\end{array}$ \\
\hline Pooled & $\mathrm{T}$ & $P=0.0002^{*} ; \mathrm{E}>\mathrm{C}$ & $P=0.8596$ & $\begin{array}{l}\mathrm{E}: P=0.8580 \\
\mathrm{C}: P=0.4726\end{array}$ & $\begin{array}{l}\mathrm{U}: P=0.3347 \\
\mathrm{D}: P=0.8263\end{array}$ & $\begin{array}{l}P=0.0151 ; \\
r^{2}=0.461 ; \mathrm{m}=0.461\end{array}$ & $\begin{array}{l}+: P=0.0004^{*} \\
r^{2}=0.823 ; \mathrm{m}=0.0183 \\
-: P=0.0039^{*} \\
r^{2}=0.675 ; \mathrm{m}=-0.145\end{array}$ & $\begin{array}{l}+: P<0.0001^{*} \\
r^{2}=0.904 ; \mathrm{m}=3.297 \\
-: P=0.0005^{*} \\
r^{2}=0.785 ; \mathrm{m}=-2.586\end{array}$ \\
\hline Pooled & A & $P=0.0064^{*} ; \mathrm{E}>\mathrm{C}$ & $P=0.3517$ & $\begin{array}{l}\mathrm{E}: P=0.9473 \\
\mathrm{C}: P=0.8285\end{array}$ & $\begin{array}{l}\mathrm{U}: P=0.8240 \\
\mathrm{D}: P=0.1931\end{array}$ & $P=0.3601$ & $\begin{array}{l}+: P=0.6989 \\
-: P=0.0869\end{array}$ & $\begin{array}{l}+: P=0.1449 \\
-: P=0.0975\end{array}$ \\
\hline
\end{tabular}




\section{I. K. Bartol, M. R. Patterson and R. Mann}

When tail-first swimming data from the four size classes were pooled, mean maximum positive and negative (converted to absolute values) deviation in velocity and acceleration were found to increase with swimming speed $\left(P<0.0039 ; r^{2}>0.675\right)$ (Table 2$)$. Although linear relationships were not always detected when tail-first velocity and acceleration deviations were regressed against swimming speed and examined separately by size class, $P$-values of less than 0.10 were frequently observed (Table 2). No linear relationships between mean maximum velocity deviation and speed and mean maximum acceleration deviation and speed were detected for squid swimming in the arms-first orientation $(P>0.05)$.

\section{Flow visualization}

On the basis of velocity measurements of particles expelled by squid during swimming, all three propulsion efficiencies were lowest at $3 \mathrm{cms}^{-1}$ and highest at $9 \mathrm{cms}^{-1}$, and arms-first propulsive efficiencies were generally higher than tail-first efficiencies (Table 3). Rocket motor propulsive efficiencies were consistently higher than Froude propulsion efficiencies and, on average, whole-cycle efficiencies were lower than both Froude and rocket motor propulsion efficiencies.

When dye or milk was injected into the mantle of squid (mean DML $4.2 \mathrm{~cm}$ ), the squid appeared agitated and frequently jetted abruptly and erratically across the aquarium or into the aquarium walls. During these episodes, the jet wake was generally very turbulent, and no vortex ring formation was observed. However, on several occasions, the squid swam across the aquarium (often beginning from rest), achieving a speed of $8.6 \pm 2.5 \mathrm{~cm} \mathrm{~s}^{-1}$, and several vortex rings formed in the jet wake. The mean ring radius was $4.8 \pm 1.2 \mathrm{~cm}$ and the mean jet core radius was $2.6 \pm 0.8 \mathrm{~cm}$ (means \pm S.D., $N=2$ ).

Obvious flow separation and the subsequent migration of flow along the body in a retrograde flow direction was observed when the mantle and arms of models were both positioned at more than $30^{\circ}$ relative to flow, irrespective of whether the models were positioned tail- or arms-first. Separation was also observed when the leading body section,

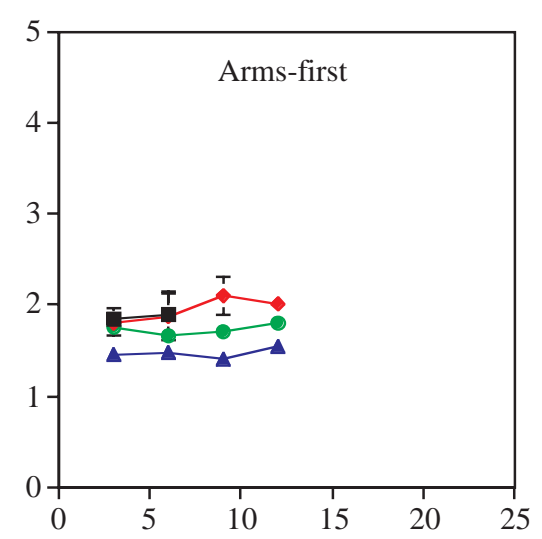

$1.0-2.9 \mathrm{~cm}$ DML: $y=0.11 x+2.03, r^{2}=0.98, P=0.0002$

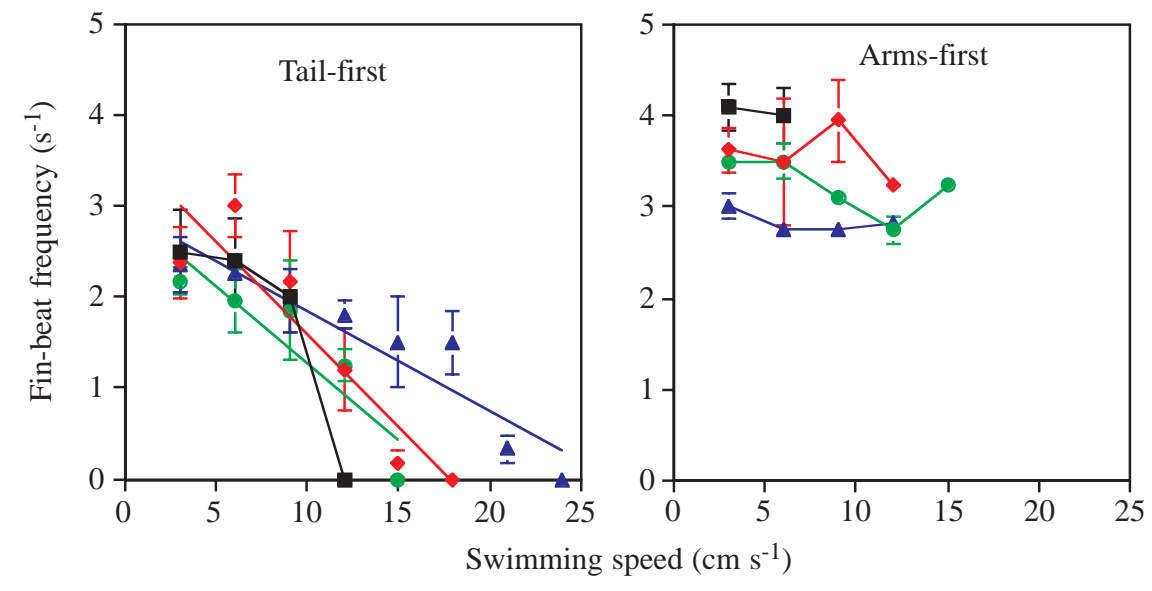

3.0-4.9 cm DML: $y=-0.20 x+3.62, r^{2}=0.86, P=0.006$

5.0-6.9 cm DML: $y=-0.17 x+2.96, r^{2}=0.83, P=0.007$

$7.0-8.9 \mathrm{~cm} D M L: y=-0.11 x+2.94, r^{2}=0.88, P=0.0006$

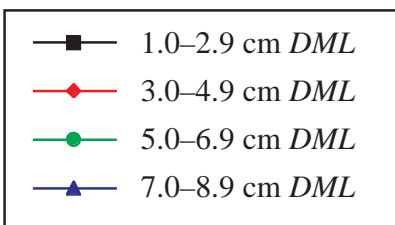

Fig. 4. Mantle contractions frequency and fin-beat frequency for Lolliguncula brevis swimming against a steady current in a flume over a range of speeds in both tail-first and arms-first orientations. Data from four size classes are depicted: $1.0-2.9 \mathrm{~cm}, 3.0-4.9 \mathrm{~cm}, 5.0-6.9 \mathrm{~cm}$ and $7.0-8 \mathrm{~cm}$ dorsal mantle length $(D M L)$. When significant linear relationships were detected, regression lines were plotted, and regression equations, $r^{2}$ values and $P$ values were included underneath graphs. All error bars represent \pm 1 S.E.M. $(N=3)$.

i.e. the mantle when in the tail-first swimming mode or the arms when in the arms-first swimming mode, was at $0^{\circ}$ and the trailing body section was positioned at more than $30^{\circ}$. However, when the leading body section was at $10-20^{\circ}$, separation did not occur until the trailing section was at $40^{\circ}$ or more. During tail-first swimming, no squid positioned its mantle at a higher angle of attack than its arms, but during arms-first swimming, angles of attack of the arms were occasionally observed to be higher than those of the mantle. In flow visualization experiments using models oriented arms-first, separation occurred whenever the arms were at angles of attack $10-15^{\circ}$ greater than that of the mantle. 

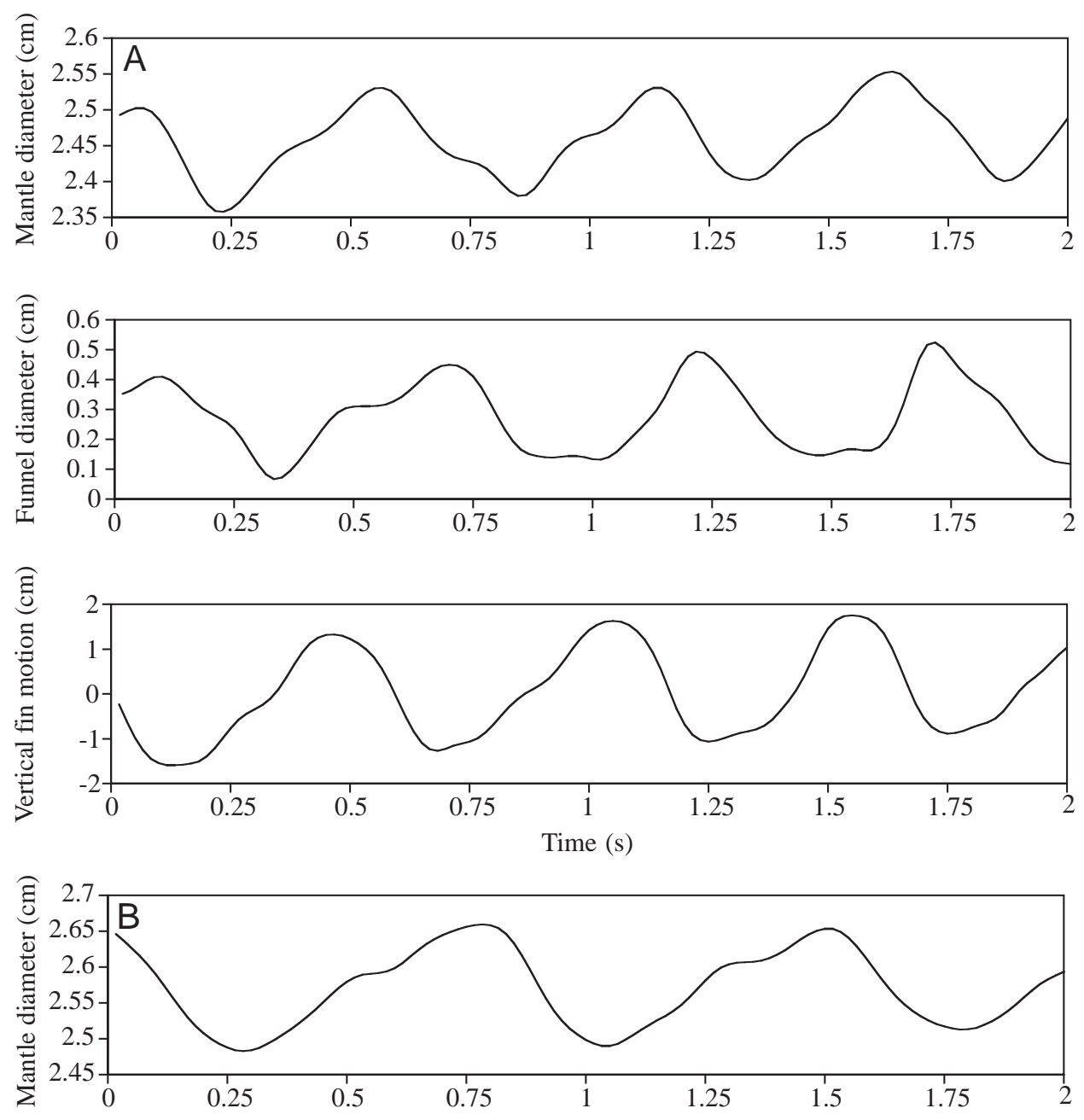

Fig. 5. Mantle diameter, funnel diameter and vertical fin motion (relative to the point where the fin connects to the mantle) of a Lolliguncula brevis $(7.3 \mathrm{~cm}$ in dorsal mantle length, DML) swimming (A) tail-first and (B) arms-first at $9 \mathrm{~cm} \mathrm{~s}^{-1}$ against a steady flow in a flume. For each swimming orientation, 60 frames were analyzed to generate the traces.

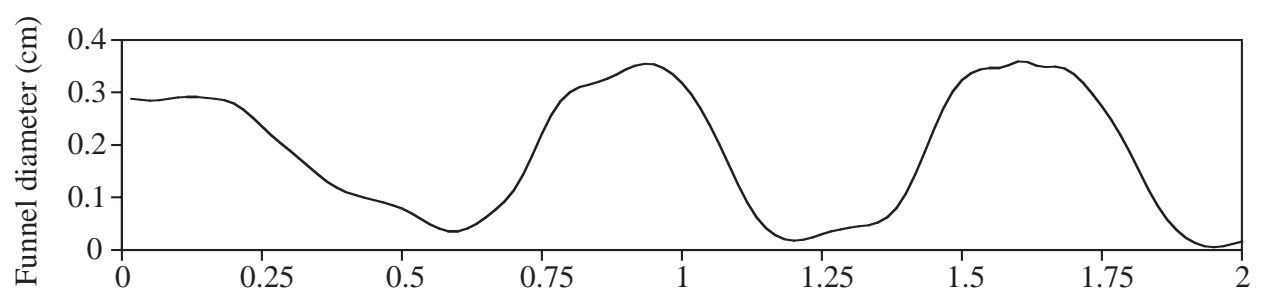

\section{Force measurements}

Polar diagrams of drag and lift coefficients calculated from squid models with extended fins positioned in both tail-first and arms-first orientations in a water tunnel are depicted in Fig. 7. The symbols displayed on the figure represent the various mantle angles of attack, while the degree designations in colour on the figures represent arm angles of attack. (Only mantle/arm

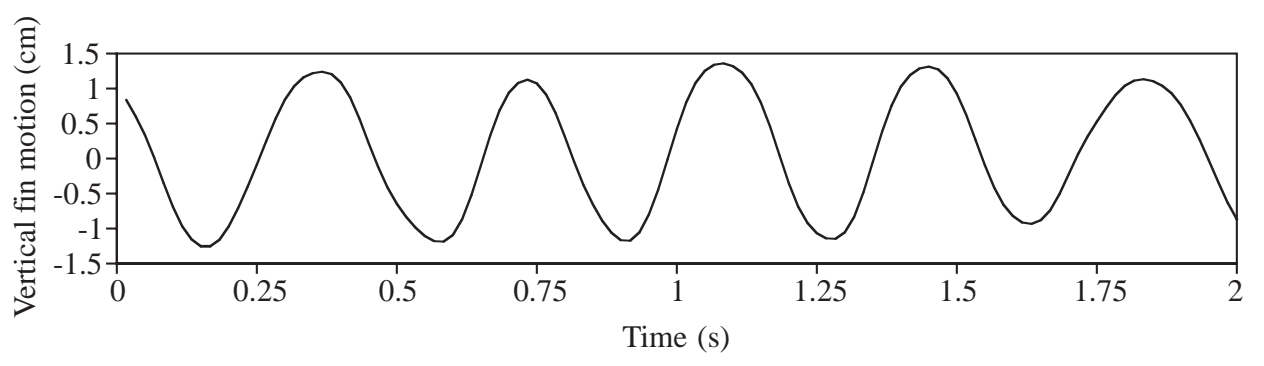

angle combinations observed in video footage of swimming squid were included in the figures.) For the mantle/arm angle combinations considered, the highest lift-to-drag ratios for tailfirst swimming were detected at mantle/arm angle combinations of $0 \% 30^{\circ}$ (2.34) and $10^{\circ} / 20^{\circ}$ (2.27) (Fig. 7). The highest lift-to-drag ratios for arms-first swimming were detected at mantle/arm angles of $20^{\circ} / 0^{\circ}$ (3.02) and $20 \% 10^{\circ}$ 
3668 I. K. Bartol, M. R. Patterson and R. Mann

Table 3. Froude propulsion, rocket motor propulsion and whole-cycle propulsion efficiencies for Lolliguncula brevis swimming in both tail-first and arms-first orientations

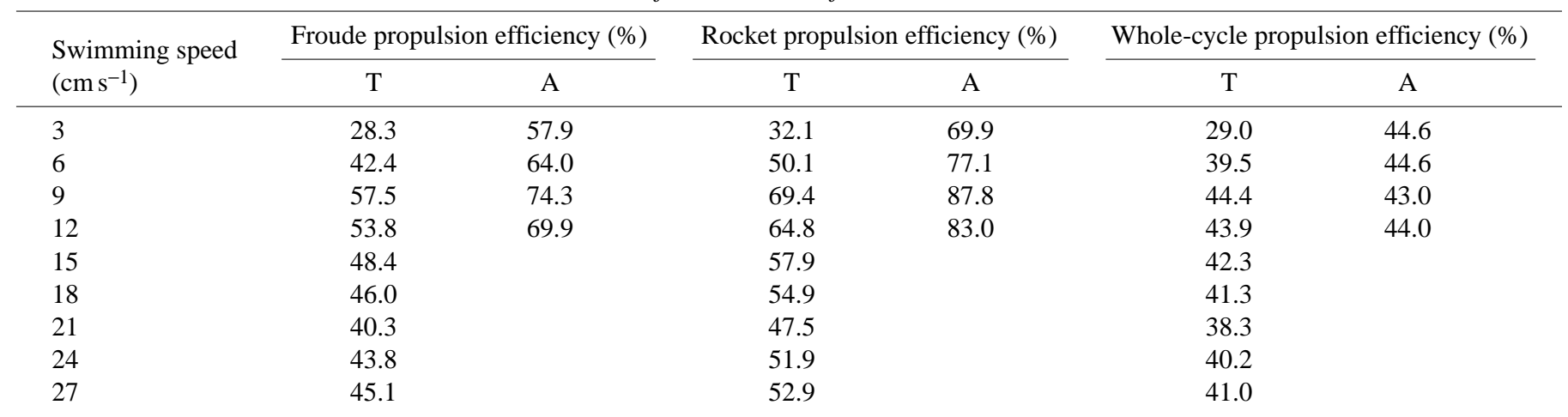

A, arms-first; T, tail-first.

Since the majority of squid did not swim at speeds above $12 \mathrm{~cm} \mathrm{~s}^{-1}$ in the arms-first mode, arms-first efficiencies were only calculated for speeds of $3-12 \mathrm{~cm} \mathrm{~s}^{-1}$.

Fig. 6. Mantle expansion and vertical fin motion (absolute vertical distance between maximum upstroke and downstroke) plotted over a range of swimming speeds for Lolliguncula brevis swimming in both tail-first and arms-first orientations. Data from four size classes are depicted: $1.0-2.9 \mathrm{~cm}$, $3.0-4.9 \mathrm{~cm}, 5.0-6.9 \mathrm{~cm}$ and $7.0-8.9 \mathrm{~cm}$ dorsal mantle length $(D M L)$. When significant linear relationships were detected, regression lines were plotted, and regression equations, $r^{2}$ values and $P$ values were included underneath graphs. All error bars represent \pm 1 S.E.M. $(N=3)$.
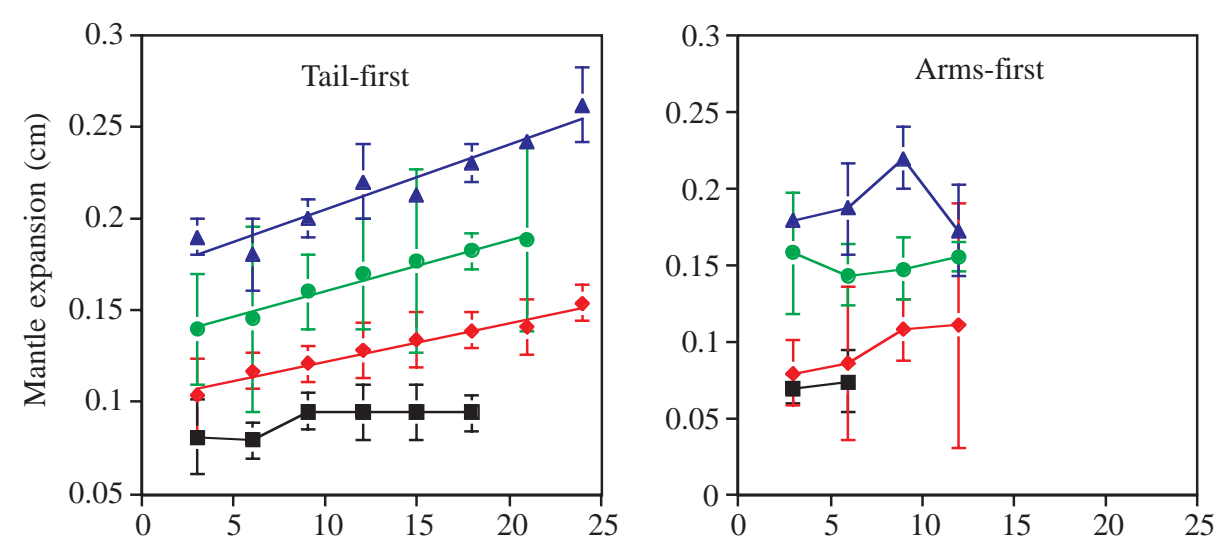

3.0-4.9 cm DML: $y=0.002 x+0.10, r^{2}=0.97, P<0.0001$

5.0-6.9 cm DML: $y=0.003 x+0.14, r^{2}=0.97, P<0.0001$

7.0-8.9 cm DML: $y=0.004 x+0.17, r^{2}=0.92, P=0.0002$
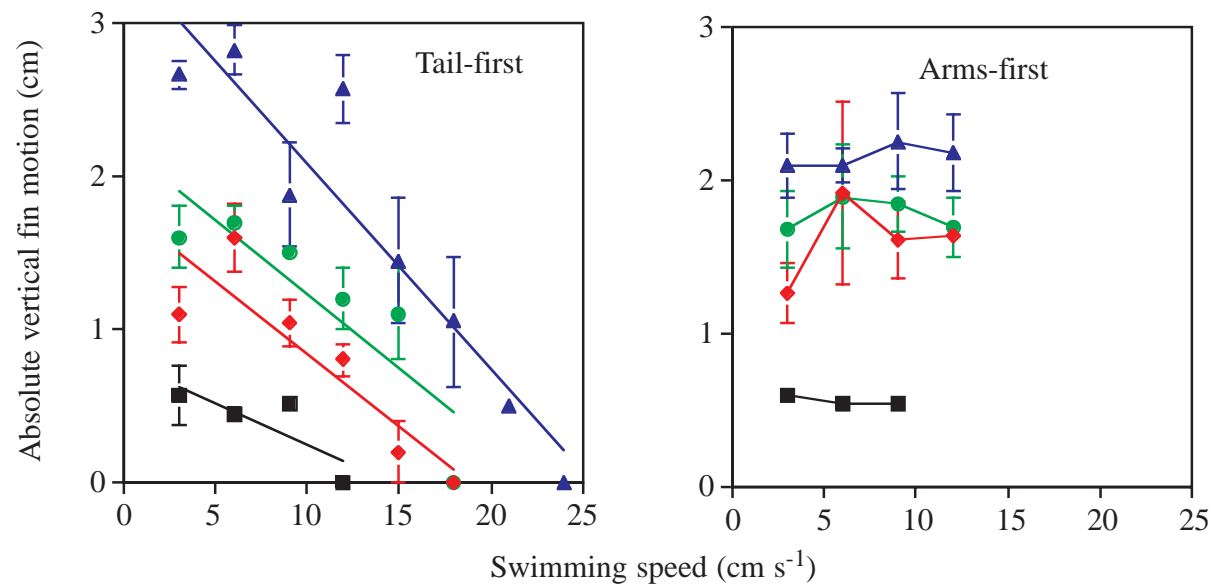

1.0-2.9 cm DML: $y=-0.055 x+0.79, r^{2}=0.67, P=0.043$

3.0-4.9 cm DML: $y=-0.095 x+1.78, r^{2}=0.79, P=0.018$

5.0-6.9 cm DML: $y=-0.096 x+2.19, r^{2}=0.75, P=0.026$

7.0-8.9 cm DML: $y=-0.13 x+3.43, r^{2}=0.88, P=0.0005$

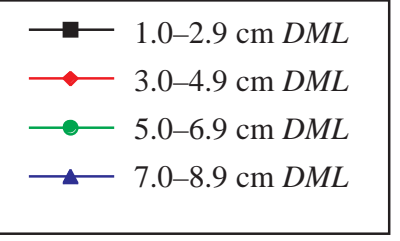



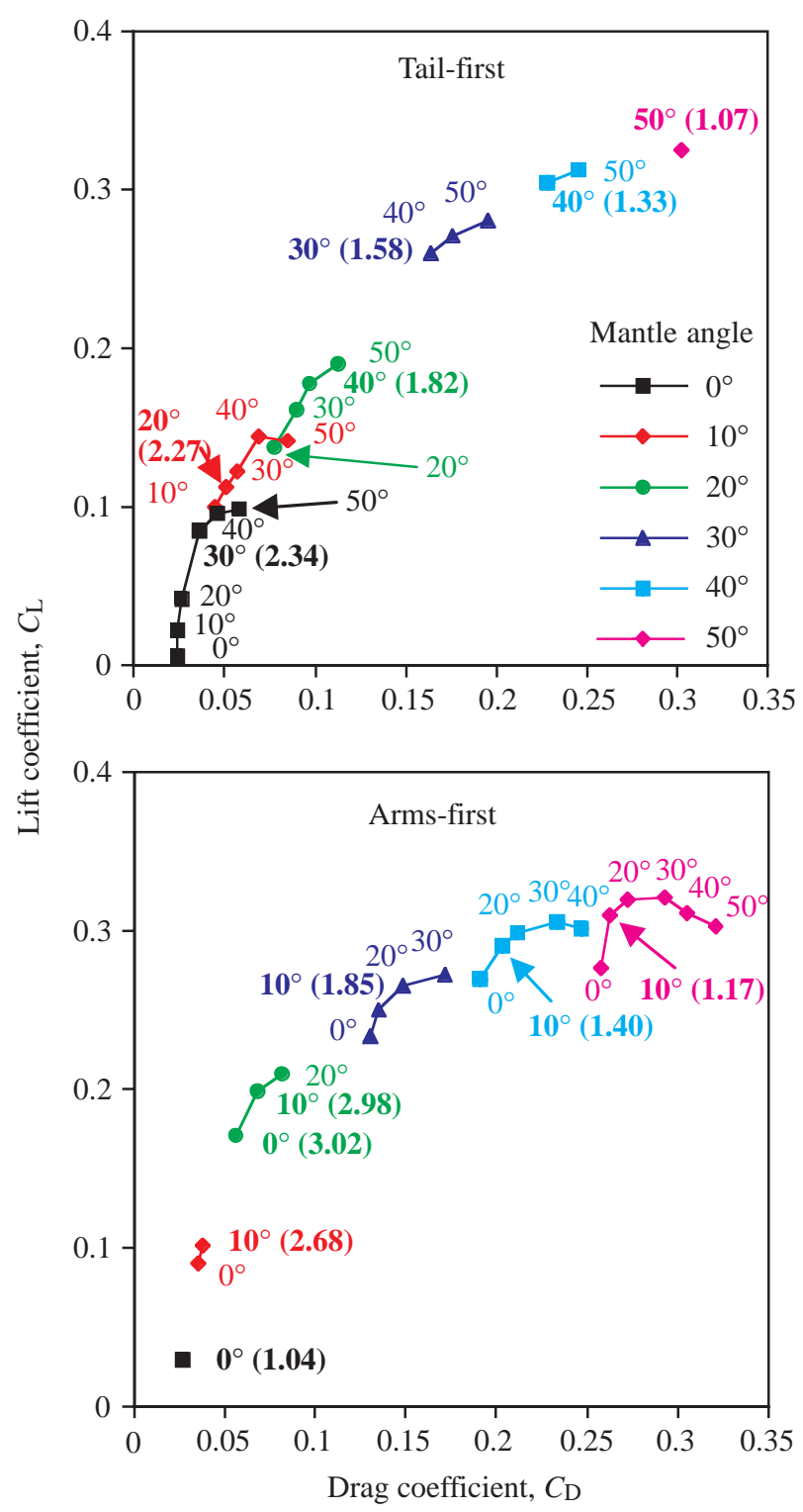

Fig. 7. Polar diagrams of drag $\left(C_{\mathrm{D}}\right)$ and lift $\left(C_{\mathrm{L}}\right)$ coefficients calculated from squid models (with fins) oriented tail-first and armsfirst relative to the free-stream flow. The various symbols, which are described in the figure, represent the angles of attack of the mantle. Degree markings within the figures represent angles of attack of the arms. Only mantle/arm angle combinations observed during swimming trials of brief squid are represented. At each mantle angle, the arm angle providing the highest lift-to-drag ratio is denoted in bold type and the ratio is provided in parentheses next to the angle.

(2.98). On the basis of video footage of tail-first swimming, mean mantle/arm angle combinations over all size classes for low $\left(3 \mathrm{~cm} \mathrm{~s}^{-1}\right)$, intermediate $\left(12 \mathrm{~cm} \mathrm{~s}^{-1}\right)$ and high $\left(21 \mathrm{~cm} \mathrm{~s}^{-1}\right)$ speeds were $20.9^{\circ} / 33.4^{\circ}, 10.1^{\circ} / 17.8^{\circ}$ and $8.7^{\circ} / 10.7^{\circ}$, respectively. Lift-to-drag ratios were therefore 1.78 for low speeds, 2.27 for intermediate speeds and 2.26 for high speeds. On the basis of video footage of arms-first swimming, mean mantle/arm angle combinations for low $\left(3 \mathrm{~cm} \mathrm{~s}^{-1}\right)$ and intermediate $\left(12 \mathrm{~cm} \mathrm{~s}^{-1}\right)$ speeds were $24.2 \% / 18.8^{\circ}$ and $8.8^{\circ} / 6.3^{\circ}$, respectively (squid did not swim arms-first at high speeds). Lift-to-drag ratios for low and intermediate speeds were 2.18 and 2.68 , respectively. On the basis of force measurements collected from models with and without fins, the fins contributed $10-51 \%$ of the total drag force and $0-65 \%$ of the total lift force for mantle angles of attack between 0 and $40^{\circ}$ during tail-first swimming and $15-61 \%$ of the total drag force and $4-68 \%$ of the total lift force for mantle angles of attack between 0 and $40^{\circ}$ during arms-first swimming.

Added mass coefficients calculated from force measurements collected from squid models are plotted in Fig. 8. Added mass coefficients increased exponentially as the angle of attack of the mantle and arms increased, irrespective of whether the models were positioned in the tail-first or armsfirst orientation.

\section{Hydrodynamics}

Resistive and propulsive forces acting on three squid $(1.8 \mathrm{~cm}, 4.4 \mathrm{~cm}$ and $7.6 \mathrm{~cm}$ in $D M L)$ swimming tail-first and arms-first over a range of speeds are displayed in Table 4. For all three squid, buoyant weight was greater than lift and vertical jet thrust for swimming velocities at and below $12-15 \mathrm{~cm} \mathrm{~s}^{-1}$ (see negative values in vertical force balance column of Table 4 and balance of forces in Fig. 9). Fin thrust was not calculated directly, but the force imbalance between buoyant weight, lift and vertical jet thrust may serve as a good approximation of vertical fin thrust, especially since there was little net change in altitude from the beginning to the end of the video sequences (vertical change $<0.9 \mathrm{~cm}$; Table 4 ). On the basis of the vertical force imbalance, the potential contribution of the fins to upward-directed forces was substantial at low speeds (3-6 $\left.\mathrm{cm} \mathrm{s}^{-1}\right)$, ranging from 28.4 to $78.6 \%$ when models with fins were considered in force balance equations and from 42.9 to $83.8 \%$ when models without fins were considered. The contribution of the fins to upward-directed forces decreased with increasing speed. Fin activity ceased at 12, 15 and $18 \mathrm{~cm} \mathrm{~s}^{-1}$ for $1.8,4.4$ and $7.6 \mathrm{~cm} \mathrm{DML} \mathrm{squid,} \mathrm{respectively,} \mathrm{and}$ fin use predictions were in reasonable agreement with these speeds. For example, only $4.1 \%$ of the upward-directed force by the $1.8 \mathrm{~cm} D M L$ squid was unaccounted for and assumed to be generated by the fins at $12 \mathrm{~cm} \mathrm{~s}^{-1}$, when no fin activity was employed.

The acceleration reaction was clearly the dominant instantaneous horizontal force (Fig. 9, Fig. 10). Although the mean acceleration reaction over a video sequence was low relative to the range of instantaneous acceleration reaction values within a series of jet cycles, mean values were nonetheless high and variable relative to the other forces (Table 4). The high variability is attributed to its sensitivity to velocity changes. Since the acceleration reaction should theoretically balance out over several jet cycles (Daniel, 1983), the horizontal force balance was calculated assuming that the mean acceleration reaction was zero for the video sequence. (If actual acceleration reaction forces were included in force balance equations, they would dominate the force balance and obscure fin thrust calculations.) On the basis of the horizontal force 
balance equation, the fins appeared to contribute significantly to horizontal thrust, especially at low speeds $\left(3-6 \mathrm{~cm} \mathrm{~s}^{-1}\right)$ when the potential contribution of the fins to horizontal thrust ranged from 32.0 to $55.1 \%$ (Table 4). As was the case for vertical fin thrust predictions, horizontal fin thrust predictions based on force balance equations were in reasonable agreement with kinematic observations; predicted horizontal fin thrust was less than $5 \%$ of the overall horizontal thrust when the fins were inactive (Table 4). A significant proportion of the drag in the horizontal direction was a product of positioning the mantle and arms at angles of attack greater than $0^{\circ}$, especially at low speeds $\left(3-6 \mathrm{~cm} \mathrm{~s}^{-1}\right)$ when as much as $91.3 \%$ of the drag was associated with the angle of attack (Table 4).

\section{Discussion \\ Lolliguncula brevis}

The data from this study indicate that Lolliguncula brevis is a slow-swimming squid that relies heavily on its fins for locomotion, is capable of swimming in two different orientations and uses various swimming strategies depending on size. Unlike other squid, such as Loligo opalescens and Illex illecebrosus, which swim for sustained periods at speeds as high as 50 and $100 \mathrm{~cm} \mathrm{~s}^{-1}$, respectively (Webber and O'Dor, 1986; O'Dor, 1988; O'Dor and Webber, 1991), L. brevis generally swims at speeds below $22 \mathrm{~cm} \mathrm{~s}^{-1}$ and swims either tail-first or arms-first at speeds below 9-15 $\mathrm{cm} \mathrm{s}^{-1}$. Because of its relatively low speed range, $L$. brevis may use its fins, muscular hydrostats that presumably operate effectively only at low/moderate speeds because of muscle and support structure constraints (Kier, 1988; Kier, 1989; O’Dor and Webber, 1991), over a larger proportion of its speed range $\left(0-18 \mathrm{~cm} \mathrm{~s}^{-1}\right)$ than Loligo opalescens or Illex illecebrosus. Consequently, the fins play a more integral role in locomotion. Moreover, not all size classes of squid appear to use the same swimming approaches, with smaller squid increasing contraction rates but keeping expelled water volume fairly constant with increasing speed, while larger squid do the opposite.

\section{Lift and stability requirements at low speeds}

As is the case with many squid species, L. brevis is negatively buoyant and consequently must generate lift to maintain position in the water column, an energetic expense that is not trivial at low speeds [see Bartol et al. (Bartol et al., 2001b)]. An important mechanism used by brief squid for lift generation at low speeds is the elevation of mantle and arm angles of attack, which induce downward flow, enhance the pressure differential above and below the body and increase lift (Vogel, 1994; Dickinson, 1996). Although the mantle and arms of squid do not resemble traditional human-made airfoils, lift may be generated when the mantle (with attached fins) and arms are positioned at high attack angles (see polar diagrams). Lift enhancement by increasing body angles of attack has also been observed in negatively buoyant fish ( $\mathrm{He}$ and Wardle, 1986; Webb, 1993), ski jumpers (Ward-Smith and Clements, 


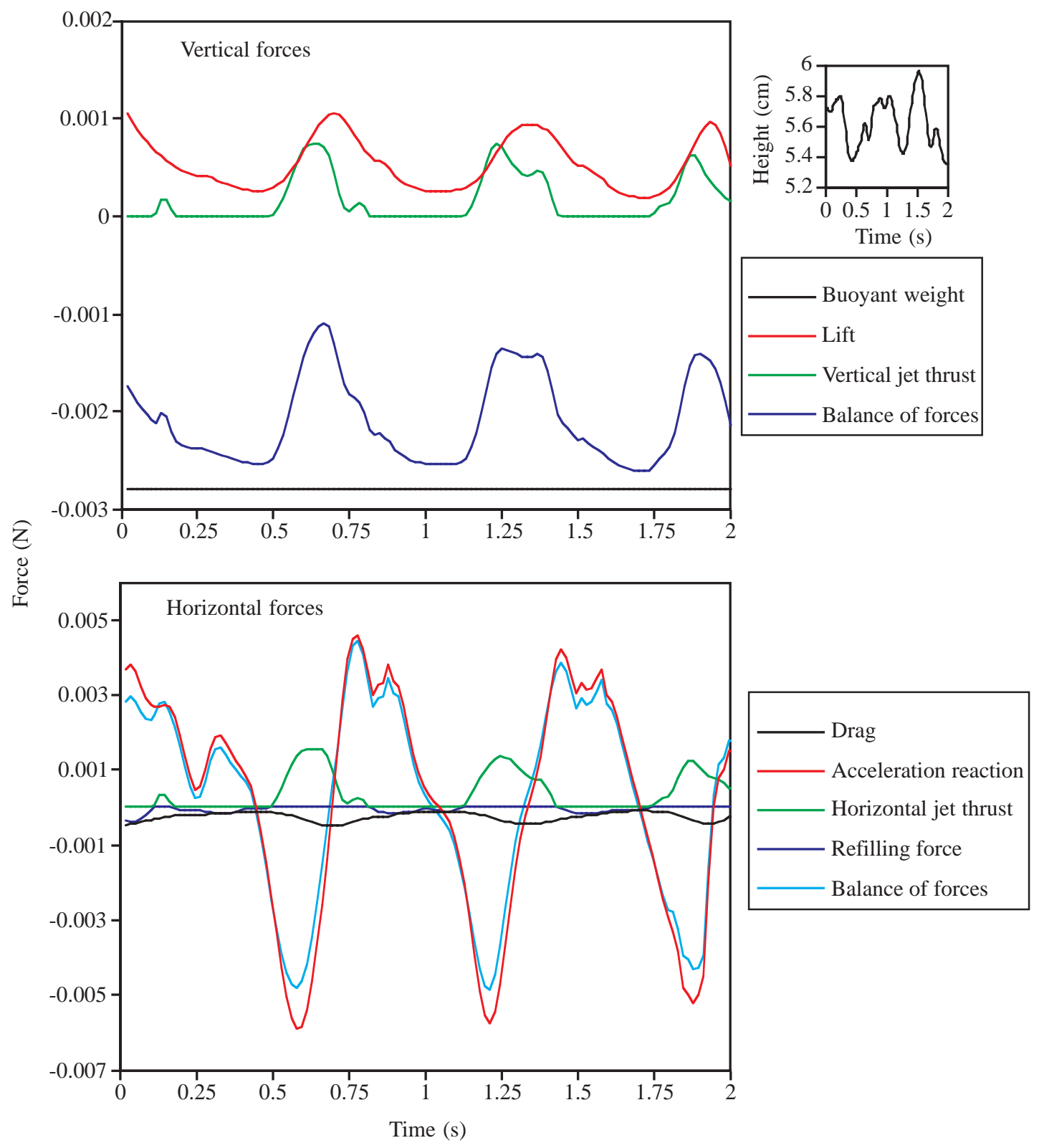

Fig. 9. Vertical and horizontal forces acting on a $4.4 \mathrm{~cm}$ Lolliguncula brevis swimming tail-first at $6 \mathrm{~cm} \mathrm{~s}^{-1}$. In the vertical forces graph, negative values represent forces acting towards the flume floor (i.e. buoyant weight), whereas in the horizontal forces graph negative values represent forces acting in the direction of free-stream flow (e.g. drag). Since there was some net altitude change over the $2 \mathrm{~s}$ video sequence, the height of $L$. brevis above the flume floor is displayed next to the vertical forces graph. There was no net horizontal change over the video sequence. Fin thrust contributions are not included in the figure.

1982), honeybees (Nachtigall and Hanauer-Thieser, 1992), birds (Tobalske and Dial, 1996) and rays (Heine, 1992).

The trailing body section (i.e. the arms or mantle depending on swimming orientation) was frequently positioned at higher angles of attack than the leading body section. Flow visualization and lift measurement studies using squid models indicate that positioning the trailing body section at higher angles of attack than the leading body section delays flow separation (when coupled with appropriate leading body section angles) and elevates lift production during both tailfirst and arms-first swimming. This is analogous to control surfaces on aircraft wings, such as ailerons or Fowler flaps, which are located on the trailing edge of the wing and positioned at higher angles of attack than the main wing (and often extended) to increase lift (Bertin and Smith, 1989; Kundu, 1990; Munson and Cronin, 1998). Just as pilots make fine lift adjustments with ailerons, squid in the tail-first swimming mode frequently adjusted the angles of attack of their arms (trailing body section) throughout the jet cycle and extended their arms to increase surface area, especially during refilling to generate extra lift when the jet was no longer producing any downward-directed thrust. At low speeds, the 
Table 4. Mean resistive and propulsive forces computed for three Lolliguncula brevis $(1.8 \mathrm{~cm}, 4.4 \mathrm{~cm}$ and $7.6 \mathrm{~cm}$ in dorsal mantle length) swimming in both tail-first and arms-first orientations over a range of speeds in a flume

\begin{tabular}{|c|c|c|c|c|c|c|c|c|c|c|c|c|c|}
\hline $\begin{array}{l}\text { Squid } \\
\text { size } \\
(\mathrm{cm} \\
D M L)\end{array}$ & $\begin{array}{l}\text { Swimming } \\
\text { velocity } \\
\left(\mathrm{cm} \mathrm{s}^{-1}\right) \\
\text { and } \\
\text { orientation }\end{array}$ & $\begin{array}{l}\text { Change } \\
\text { of } \\
\text { altitude } \\
(\mathrm{cm})\end{array}$ & $\begin{array}{l}\text { Lift } \\
(\mathrm{N})\end{array}$ & $\begin{array}{l}\text { Vertical } \\
\text { jet thrust } \\
(\mathrm{N})\end{array}$ & $\begin{array}{l}\text { I } \\
\text { Vertical } \\
\text { force } \\
\text { balance } \\
\text { (N) }\end{array}$ & $\begin{array}{l}\text { Potential \% } \\
\text { contribution } \\
\text { of fins to } \\
\text { upward- } \\
\text { directed } \\
\text { forces }\end{array}$ & $\begin{array}{l}\text { Drag } \\
(\mathrm{N})\end{array}$ & $\begin{array}{l}\text { Refilling } \\
\text { force } \\
(\mathrm{N})\end{array}$ & $\begin{array}{l}\text { Horizontal } \\
\text { jet thrust } \\
(\mathrm{N})\end{array}$ & $\begin{array}{l}\text { Horizontal } \\
\text { force balance } \\
\text { without } \\
\text { acceleration } \\
\text { reaction } \\
\text { (N) }\end{array}$ & $\begin{array}{l}\text { Potential \% } \\
\text { contribution } \\
\text { of fins to } \\
\text { horizontal } \\
\text { thrust }\end{array}$ & $\begin{array}{l}\text { Acceleration } \\
\text { reaction } \\
\text { over video } \\
\text { sequence } \\
\text { (N) }\end{array}$ & $\begin{array}{c}\% \text { of drag } \\
\text { associated } \\
\text { with angle } \\
\text { of attack }\end{array}$ \\
\hline 1.8 & $3 \mathrm{~T}$ & +0.408 & $\begin{array}{c}2.67 \times 10^{-5} \\
\left(1.86 \times 10^{-5}\right)\end{array}$ & $3.93 \times 10^{-5}$ & $\begin{array}{c}-1.54 \times 10^{-4} \\
\left(-1.62 \times 10^{-4}\right)\end{array}$ & $\begin{array}{c}70.1 \\
(73.7)\end{array}$ & $-1.28 \times 10^{-5}$ & $-5.04 \times 10^{-6}$ & $1.10 \times 10^{-5}$ & $-6.84 \times 10^{-6}$ & 38.2 & $-4.12 \times 10^{-5}$ & 65.5 \\
\hline 1.8 & $3 \mathrm{~A}$ & +0.104 & $\begin{array}{c}2.81 \times 10^{-5} \\
\left(1.90 \times 10^{-5}\right)\end{array}$ & $4.11 \times 10^{-5}$ & $\begin{array}{c}-1.52 \times 10^{-4} \\
\left(-1.60 \times 10^{-4}\right)\end{array}$ & $\begin{array}{c}68.5 \\
(72.6)\end{array}$ & $-1.21 \times 10^{-5}$ & $-6.73 \times 10^{-6}$ & $1.00 \times 10^{-5}$ & $-8.83 \times 10^{-6}$ & 46.7 & $4.27 \times 10^{-6}$ & 62.3 \\
\hline 1.8 & $6 \mathrm{~T}$ & +0.0920 & $\begin{array}{c}1.24 \times 10^{-4} \\
\left(9.17 \times 10^{-5}\right)\end{array}$ & $3.39 \times 10^{-5}$ & $\begin{array}{c}-6.25 \times 10^{-5} \\
\left(-9.44 \times 10^{-5}\right)\end{array}$ & $\begin{array}{c}28.4 \\
(42.9)\end{array}$ & $-6.48 \times 10^{-5}$ & $-1.57 \times 10^{-5}$ & $5.21 \times 10^{-5}$ & $-2.84 \times 10^{-5}$ & 35.3 & $6.59 \times 10^{-6}$ & 72.8 \\
\hline 1.8 & $6 \mathrm{~A}$ & +0.0311 & $\begin{array}{c}1.14 \times 10^{-4} \\
\left(7.76 \times 10^{-5}\right)\end{array}$ & $3.51 \times 10^{-5}$ & $\begin{array}{c}-7.08 \times 10^{-5} \\
\left(-1.07 \times 10^{-4}\right)\end{array}$ & $\begin{array}{c}32.2 \\
(48.8)\end{array}$ & $-6.53 \times 10^{-5}$ & $-1.32 \times 10^{-5}$ & $5.14 \times 10^{-5}$ & $-2.71 \times 10^{-5}$ & 34.5 & $-1.78 \times 10^{-6}$ & 65.1 \\
\hline 1.8 & $9 \mathrm{~T}$ & -0.0841 & $\begin{array}{c}1.34 \times 10^{-4} \\
\left(1.21 \times 10^{-4}\right)\end{array}$ & $3.73 \times 10^{-5}$ & $\begin{array}{c}-4.86 \times 10^{-5} \\
\left(-6.21 \times 10^{-5}\right)\end{array}$ & $\begin{array}{r}22.9 \\
(28.2) \\
\end{array}$ & $-9.53 \times 10^{-5}$ & $-1.58 \times 10^{-5}$ & $7.95 \times 10^{-5}$ & $-3.16 \times 10^{-5}$ & $\underline{28.4}$ & $-9.67 \times 10^{-7}$ & 60.4 \\
\hline 1.8 & $12 \mathrm{~T}$ & +0.312 & $\left(1.58 \times 10^{-4}\right)$ & $5.31 \times 10^{-5}$ & $\left(-9.03 \times 10^{-6}\right)$ & (4.1) & $\left(-9.30 \times 10^{-5}\right)$ & $-4.00 \times 10^{-5}$ & $1.31 \times 10^{-4}$ & $\left(-2.10 \times 10^{-6}\right)$ & (1.6) & $-1.32 \times 10^{-5}$ & 24.3 \\
\hline 1.8 & $15 \mathrm{~T}$ & -0.915 & $\left(1.61 \times 10^{-4}\right)$ & $7.39 \times 10^{-5}$ & $\left(+1.49 \times 10^{-5}\right)$ & 0 & $\left(-1.15 \times 10^{-4}\right)$ & $-5.22 \times 10^{-5}$ & $1.66 \times 10^{-4}$ & $\left(-1.20 \times 10^{-6}\right)$ & $(0.7)$ & $9.35 \times 10^{-6}$ & 13.0 \\
\hline 1.8 & $18 \mathrm{~T}$ & -0.274 & $\left(2.11 \times 10^{-4}\right)$ & $9.44 \times 10^{-5}$ & $\left(+8.51 \times 10^{-5}\right)$ & 0 & $\left(-1.81 \times 10^{-4}\right)$ & $-7.35 \times 10^{-5}$ & $2.81 \times 10^{-4}$ & $\left(+2.65 \times 10^{-5}\right)$ & 0 & $5.56 \times 10^{-5}$ & 12.1 \\
\hline 4.4 & $3 \mathrm{~T}$ & +0.034 & $\begin{array}{c}2.37 \times 10^{-4} \\
\left(1.23 \times 10^{-4}\right)\end{array}$ & $3.31 \times 10^{-4}$ & $\begin{array}{l}-2.21 \times 10^{-3} \\
\left(2.34 \times 10^{-3}\right)\end{array}$ & $\begin{array}{c}78.6 \\
(83.8)\end{array}$ & $-1.32 \times 10^{-4}$ & $-2.67 \times 10^{-5}$ & $1.03 \times 10^{-4}$ & $-5.60 \times 10^{-5}$ & 35.3 & $2.73 \times 10^{-4}$ & 77.0 \\
\hline 4.4 & $3 \mathrm{~A}$ & +0.627 & $\begin{array}{c}3.41 \times 10^{-4} \\
\left(2.19 \times 10^{-4}\right)\end{array}$ & $3.66 \times 10^{-4}$ & $\begin{array}{c}-2.12 \times 10^{-3} \\
\left(-2.21 \times 10^{-3}\right)\end{array}$ & $\begin{array}{c}75.0 \\
(79.1)\end{array}$ & $-1.49 \times 10^{-4}$ & $-8.78 \times 10^{-5}$ & $1.27 \times 10^{-4}$ & $-1.15 \times 10^{-4}$ & 48.6 & $-1.23 \times 10^{-4}$ & 77.9 \\
\hline 4.4 & $6 \mathrm{~T}$ & -0.312 & $\begin{array}{c}5.64 \times 10^{-4} \\
\left(5.08 \times 10^{-4}\right)\end{array}$ & $3.95 \times 10^{-4}$ & $\begin{array}{l}-1.84 \times 10^{-3} \\
\left(1.90 \times 10^{-3}\right)\end{array}$ & $\begin{array}{c}65.7 \\
(67.7)\end{array}$ & $-2.60 \times 10^{-4}$ & $-8.48 \times 10^{-5}$ & $2.34 \times 10^{-4}$ & $-1.11 \times 10^{-4}$ & 32.0 & $2.74 \times 10^{-4}$ & 53.4 \\
\hline 4.4 & $6 \mathrm{~A}$ & +0.0430 & $\begin{array}{c}5.76 \times 10^{-4} \\
\left(5.20 \times 10^{-4}\right)\end{array}$ & $4.42 \times 10^{-4}$ & $\begin{array}{c}-1.78 \times 10^{-3} \\
\left(-1.84 \times 10^{-3}\right)\end{array}$ & $\begin{array}{c}63.6 \\
(65.6)\end{array}$ & $-2.45 \times 10^{-4}$ & $-8.35 \times 10^{-5}$ & $2.06 \times 10^{-4}$ & $-1.20 \times 10^{-4}$ & 36.8 & $-1.84 \times 10^{-4}$ & 46.4 \\
\hline 4.4 & $9 \mathrm{~T}$ & -0.0337 & $\begin{array}{c}1.24 \times 10^{-3} \\
\left(1.12 \times 10^{-3}\right)\end{array}$ & $4.60 \times 10^{-4}$ & $\begin{array}{c}-1.12 \times 10^{-3} \\
\left(-1.22 \times 10^{-3}\right)\end{array}$ & $\begin{array}{c}39.3 \\
(43.7)\end{array}$ & $-5.71 \times 10^{-4}$ & $-1.31 \times 10^{-4}$ & $5.15 \times 10^{-4}$ & $-1.80 \times 10^{-4}$ & 25.6 & $3.84 \times 10^{-4}$ & 52.2 \\
\hline 4.4 & $9 \mathrm{~A}$ & +0.0540 & $\begin{array}{c}1.31 \times 10^{-3} \\
\left(1.18 \times 10^{-3}\right)\end{array}$ & $5.29 \times 10^{-4}$ & $\begin{array}{c}-9.62 \times 10^{-4} \\
\left(-1.09 \times 10^{-3}\right)\end{array}$ & $\begin{array}{c}34.3 \\
(39.0)\end{array}$ & $-5.61 \times 10^{-4}$ & $-1.54 \times 10^{-4}$ & $5.00 \times 10^{-4}$ & $-2.15 \times 10^{-4}$ & 30.1 & $2.93 \times 10^{-4}$ & 47.4 \\
\hline 4.4 & $12 \mathrm{~T}$ & -0.0900 & $\begin{array}{c}2.20 \times 10^{-3} \\
\left(1.98 \times 10^{-3}\right)\end{array}$ & $5.00 \times 10^{-4}$ & $\begin{array}{c}-1.04 \times 10^{-4} \\
\left(-3.20 \times 10^{-4}\right)\end{array}$ & $\begin{array}{c}3.7 \\
(11.4)\end{array}$ & $-9.09 \times 10^{-4}$ & $-2.27 \times 10^{-4}$ & $9.56 \times 10^{-4}$ & $-1.74 \times 10^{-4}$ & 14.9 & $-2.95 \times 10^{-4}$ & 46.6 \\
\hline 4.4 & $12 \mathrm{~A}$ & +0.0825 & $\begin{array}{c}2.48 \times 10^{-3} \\
\left(2.21 \times 10^{-3}\right)\end{array}$ & $5.15 \times 10^{-4}$ & $\begin{array}{c}+1.94 \times 10^{-4} \\
\left(-7.78 \times 10^{-5}\right)\end{array}$ & $\begin{array}{c}0 \\
(2.8) \\
\end{array}$ & $-8.27 \times 10^{-4}$ & $-2.12 \times 10^{-4}$ & $7.81 \times 10^{-4}$ & $-2.58 \times 10^{-4}$ & 24.7 & $-1.35 \times 10^{-5}$ & 36.5 \\
\hline 4.4 & $15 \mathrm{~T}$ & +0.325 & $\left(2.32 \times 10^{-3}\right)$ & $4.34 \times 10^{-4}$ & $\left(-4.60 \times 10^{-5}\right)$ & (1.6) & $\left(-1.11 \times 10^{-3}\right)$ & $-2.87 \times 10^{-4}$ & $1.36 \times 10^{-3}$ & $\left(-3.70 \times 10^{-5}\right)$ & (2.6) & $4.50 \times 10^{-5}$ & 31.8 \\
\hline 4.4 & $18 \mathrm{~T}$ & -0.188 & $\left(2.25 \times 10^{-3}\right)$ & $6.97 \times 10^{-4}$ & $\left(+1.51 \times 10^{-4}\right)$ & 0 & $\left(-2.00 \times 10^{-3}\right)$ & $-3.27 \times 10^{-4}$ & $2.42 \times 10^{-3}$ & $\left(+9.30 \times 10^{-5}\right)$ & 0 & $-3.05 \times 10^{-4}$ & 25.8 \\
\hline 4.4 & $21 \mathrm{~T}$ & +0.027 & $\left(2.93 \times 10^{-3}\right)$ & $6.91 \times 10^{-4}$ & $\left(+8.21 \times 10^{-4}\right)$ & 0 & $\left(-2.29 \times 10^{-3}\right)$ & $-4.44 \times 10^{-4}$ & $3.13 \times 10^{-3}$ & $\left(+3.96 \times 10^{-4}\right)$ & 0 & $6.02 \times 10^{-5}$ & 35.1 \\
\hline 4.4 & $24 \mathrm{~T}$ & +0.866 & $\left(2.98 \times 10^{-3}\right)$ & $1.10 \times 10^{-3}$ & $\left(+1.28 \times 10^{-3}\right)$ & 0 & $\left(-2.64 \times 10^{-3}\right)$ & $-4.63 \times 10^{-4}$ & $3.31 \times 10^{-3}$ & $\left(+2.07 \times 10^{-4}\right)$ & 0 & $-2.45 \times 10^{-4}$ & 26.5 \\
\hline
\end{tabular}


Table 4. Continued

\begin{tabular}{|c|c|c|c|c|c|c|c|c|c|c|c|c|c|}
\hline $\begin{array}{l}\text { Squid } \\
\text { size } \\
(\mathrm{cm} \\
D M L)\end{array}$ & $\begin{array}{l}\text { Swimming } \\
\text { velocity } \\
\left(\mathrm{cm} \mathrm{s}^{-1}\right) \\
\text { and } \\
\text { orientation }\end{array}$ & $\begin{array}{l}\text { Change } \\
\text { of } \\
\text { altitude } \\
(\mathrm{cm})\end{array}$ & $\begin{array}{l}\text { Lift } \\
(\mathrm{N})\end{array}$ & $\begin{array}{l}\text { Vertical } \\
\text { jet thrust } \\
(\mathrm{N})\end{array}$ & $\begin{array}{ll} & \mathrm{I} \\
\text { Vertical } & \mathrm{c} \\
\text { force } & \\
\text { balance } & \\
(\mathrm{N}) & \end{array}$ & $\begin{array}{l}\text { Potential \% } \\
\text { contribution } \\
\text { of fins to } \\
\text { upward- } \\
\text { directed } \\
\text { forces }\end{array}$ & $\begin{array}{l}\text { Drag } \\
(\mathrm{N})\end{array}$ & $\begin{array}{l}\text { Refilling } \\
\text { force } \\
(\mathrm{N})\end{array}$ & $\begin{array}{l}\text { Horizontal } \\
\text { jet thrust } \\
\text { (N) }\end{array}$ & $\begin{array}{l}\text { Horizontal } \\
\text { force balance } \\
\text { without } \\
\text { acceleration } \\
\text { reaction } \\
(\mathrm{N})\end{array}$ & $\begin{array}{c}\text { Potential \% } \\
\text { contribution } \\
\text { of fins to } \\
\text { horizontal } \\
\text { thrust }\end{array}$ & $\begin{array}{l}\text { Acceleration } \\
\text { reaction } \\
\text { over video } \\
\text { sequence } \\
(\mathrm{N})\end{array}$ & $\begin{array}{c}\% \text { of drag } \\
\text { associated } \\
\text { with angle } \\
\text { of attack }\end{array}$ \\
\hline 7.6 & $3 \mathrm{~T}$ & -0.0893 & $\begin{array}{c}8.76 \times 10^{-4} \\
\left(3.87 \times 10^{-4}\right)\end{array}$ & $2.20 \times 10^{-3}$ & $\begin{array}{c}-7.89 \times 10^{-3} \\
\left(-8.38 \times 10^{-3}\right)\end{array}$ & $\begin{array}{c}71.9 \\
(76.4)\end{array}$ & $-7.72 \times 10^{-4}$ & $-1.78 \times 10^{-4}$ & $4.61 \times 10^{-4}$ & $-4.91 \times 10^{-4}$ & 51.5 & $-3.53 \times 10^{-4}$ & 90.2 \\
\hline 7.6 & $6 \mathrm{~T}$ & +0.107 & $\begin{array}{c}2.14 \times 10^{-3} \\
\left(1.24 \times 10^{-3}\right)\end{array}$ & $2.43 \times 10^{-3}$ & $\begin{array}{l}-6.40 \times 10^{-3} \\
\left(-7.30 \times 10^{-3}\right)\end{array}$ & $\begin{array}{c}58.3 \\
(66.5)\end{array}$ & $-1.03 \times 10^{-3}$ & $-2.81 \times 10^{-4}$ & $6.38 \times 10^{-4}$ & $-6.73 \times 10^{-4}$ & 51.3 & $+3.56 \times 10^{-3}$ & 91.3 \\
\hline 7.6 & $6 \mathrm{~A}$ & +0.196 & $\begin{array}{c}2.63 \times 10^{-3} \\
\left(1.55 \times 10^{-3}\right)\end{array}$ & $2.65 \times 10^{-3}$ & $\begin{array}{c}-5.69 \times 10^{-3} \\
\left(-6.77 \times 10^{-3}\right)\end{array}$ & $\begin{array}{c}51.8 \\
(61.7)\end{array}$ & $-1.00 \times 10^{-3}$ & $-3.00 \times 10^{-4}$ & $5.85 \times 10^{-4}$ & $-7.17 \times 10^{-4}$ & 55.1 & $-1.56 \times 10^{-3}$ & 67.3 \\
\hline 7.6 & $9 \mathrm{~T}$ & -0.0780 & $\begin{array}{c}3.37 \times 10^{-3} \\
\left(2.04 \times 10^{-3}\right)\end{array}$ & $2.77 \times 10^{-3}$ & $\begin{array}{c}-4.83 \times 10^{-3} \\
\left(-6.16 \times 10^{-3}\right)\end{array}$ & $\begin{array}{c}44.0 \\
(56.2)\end{array}$ & $-1.97 \times 10^{-3}$ & $-6.27 \times 10^{-4}$ & $1.78 \times 10^{-3}$ & $-8.17 \times 10^{-4}$ & 31.4 & $-1.14 \times 10^{-3}$ & 65.5 \\
\hline 7.6 & $9 \mathrm{~A}$ & +0.0322 & $\begin{array}{c}3.14 \times 10^{-3} \\
\left(2.31 \times 10^{-3}\right)\end{array}$ & $2.61 \times 10^{-3}$ & $\begin{array}{l}-5.22 \times 10^{-3} \\
\left(-6.05 \times 10^{-3}\right)\end{array}$ & $\begin{array}{c}47.5 \\
(55.2)\end{array}$ & $-1.73 \times 10^{-3}$ & $-7.22 \times 10^{-4}$ & $1.44 \times 10^{-3}$ & $-1.01 \times 10^{-3}$ & 41.1 & $+2.20 \times 10^{-3}$ & 61.3 \\
\hline 7.6 & $12 \mathrm{~T}$ & +0.0174 & $\begin{array}{c}5.20 \times 10^{-3} \\
\left(3.12 \times 10^{-3}\right)\end{array}$ & $3.13 \times 10^{-3}$ & $\begin{array}{c}-2.64 \times 10^{-3} \\
\left(-4.72 \times 10^{-3}\right)\end{array}$ & $\begin{array}{c}24.1 \\
(43.0)\end{array}$ & $-2.74 \times 10^{-3}$ & $-9.06 \times 10^{-4}$ & $2.42 \times 10^{-3}$ & $-1.25 \times 10^{-3}$ & 34.2 & $-7.31 \times 10^{-3}$ & 58.4 \\
\hline 7.6 & $12 \mathrm{~A}$ & -0.0645 & $\begin{array}{c}5.07 \times 10^{-3} \\
\left(2.79 \times 10^{-3}\right)\end{array}$ & $3.45 \times 10^{-3}$ & $\begin{array}{c}-2.45 \times 10^{-3} \\
\left(-4.73 \times 10^{-3}\right)\end{array}$ & $\begin{array}{c}22.4 \\
(43.1)\end{array}$ & $-2.81 \times 10^{-3}$ & $-9.51 \times 10^{-4}$ & $2.14 \times 10^{-3}$ & $-1.62 \times 10^{-3}$ & 43.2 & $-3.94 \times 10^{-3}$ & 52.2 \\
\hline 7.6 & $15 \mathrm{~T}$ & +0.787 & $\begin{array}{c}7.52 \times 10^{-3} \\
\left(6.77 \times 10^{-3}\right)\end{array}$ & $2.66 \times 10^{-3}$ & $\begin{array}{c}-7.89 \times 10^{-4} \\
\left(-1.54 \times 10^{-3}\right)\end{array}$ & $\begin{array}{r}7.2 \\
(14.0) \\
\end{array}$ & $-3.93 \times 10^{-3}$ & $-1.07 \times 10^{-3}$ & $3.86 \times 10^{-3}$ & $-1.14 \times 10^{-3}$ & $\underline{22.8}$ & $+2.20 \times 10^{-3}$ & 51.9 \\
\hline 7.6 & $18 \mathrm{~T}$ & +0.572 & $\left(7.62 \times 10^{-3}\right)$ & $4.32 \times 10^{-3}$ & $\left(+9.70 \times 10^{-4}\right)$ & 0 & $\left(-4.07 \times 10^{-3}\right)$ & $-1.22 \times 10^{-3}$ & $5.10 \times 10^{-3}$ & $\left(-1.90 \times 10^{-4}\right)$ & 3.6 & $-8.90 \times 10^{-4}$ & 33.1 \\
\hline 7.6 & $21 \mathrm{~T}$ & +0.328 & $\left(9.68 \times 10^{-3}\right)$ & $5.12 \times 10^{-3}$ & $\left(+3.83 \times 10^{-3}\right)$ & 0 & $\left(-6.81 \times 10^{-3}\right)$ & $-5.90 \times 10^{-3}$ & $1.22 \times 10^{-2}$ & $\left(-5.10 \times 10^{-4}\right)$ & 4.0 & $-3.50 \times 10^{-4}$ & 45.6 \\
\hline 7.6 & $24 \mathrm{~T}$ & +0.173 & $\left(1.10 \times 10^{-2}\right)$ & $6.03 \times 10^{-3}$ & $\left(+6.06 \times 10^{-3}\right)$ & 0 & $\left(-9.00 \times 10^{-3}\right)$ & $-8.10 \times 10^{-3}$ & $1.68 \times 10^{-2}$ & $\left(-3.00 \times 10^{-4}\right)$ & 1.7 & $+2.22 \times 10^{-4}$ & 36.3 \\
\hline $\begin{array}{l}\text { In th } \\
\text { sequen } \\
\text { acceler } \\
\text { conside } \\
\text { Line } \\
\text { In th } \\
\text { directio } \\
\text { Valu } \\
\text { DMI }\end{array}$ & $\begin{array}{l}\text { ces, which is } \\
\text { ation reactior } \\
\text { red as potent } \\
\text { in the poten } \\
\text { e vertical dir } \\
\text { n of free-stre } \\
\text { es in parenth } \\
\text {, dorsal man }\end{array}$ & $\begin{array}{l}\text { depicted i } \\
\text { n should e } \\
\text { tial fin thru } \\
\text { tial \% fin } \\
\text { rection, ne } \\
\text { eam flow (e } \\
\text { eses are ba } \\
\text { tle length; }\end{array}$ & $\begin{array}{l}\text { the change o } \\
\text { qual zero over } \\
\text { ontribution co } \\
\text { gative values } \\
\text { g. drag). } \\
\text { ed on force m } \\
\text { A, arms-first; }\end{array}$ & $\begin{array}{l}\text { st and ver } \\
\text { titude colu } \\
\text { jet cycle. } \\
\text { ans indicat } \\
\text { resent forc } \\
\text { urements f } \\
\text { ail-first. }\end{array}$ & $\begin{array}{l}\text { al fin thrust } \mathrm{m} \\
\text { n. In the horiz } \\
\text { nce vertical ar } \\
\text { where observe } \\
\text { towards the } \\
\text { m models witl }\end{array}$ & $\begin{array}{l}\text { must equal } \\
\text { zontal direct } \\
\text { and horizont } \\
\text { ed fin activit } \\
\text { flume floor } \\
\text { thout fins. }\end{array}$ & $\begin{array}{l}\text { buoyant weigh } \\
\text { tion, drag and } t \\
\text { tal fin thrust w } \\
\text { y ceased. } \\
\text { (i.e. buoyant }\end{array}$ & $\begin{array}{l}\text { t at constan } \\
\text { he refilling } \\
\text { ere not mea } \\
\text { weight); in }\end{array}$ & $\begin{array}{l}\text { evation. T } \\
\text { e should } \\
\text { ed directl } \\
\text { horizonta }\end{array}$ & $\begin{array}{l}\text { e was some } n \\
\text { al horizontal } j \\
\text { egative vertic } \\
\text { rection, negat }\end{array}$ & $\begin{array}{l}\text { inor net ch } \\
\text { et thrust and } \\
\text { al and horiz } \\
\text { ive values } r\end{array}$ & $\begin{array}{l}\text { in elevatio } \\
\text { izontal fin th } \\
\text { force imb } \\
\text { sent forces }\end{array}$ & $\begin{array}{l}\text { over video } \\
\text { ist, and the } \\
\text { ances were } \\
\text { ting in the }\end{array}$ \\
\hline
\end{tabular}




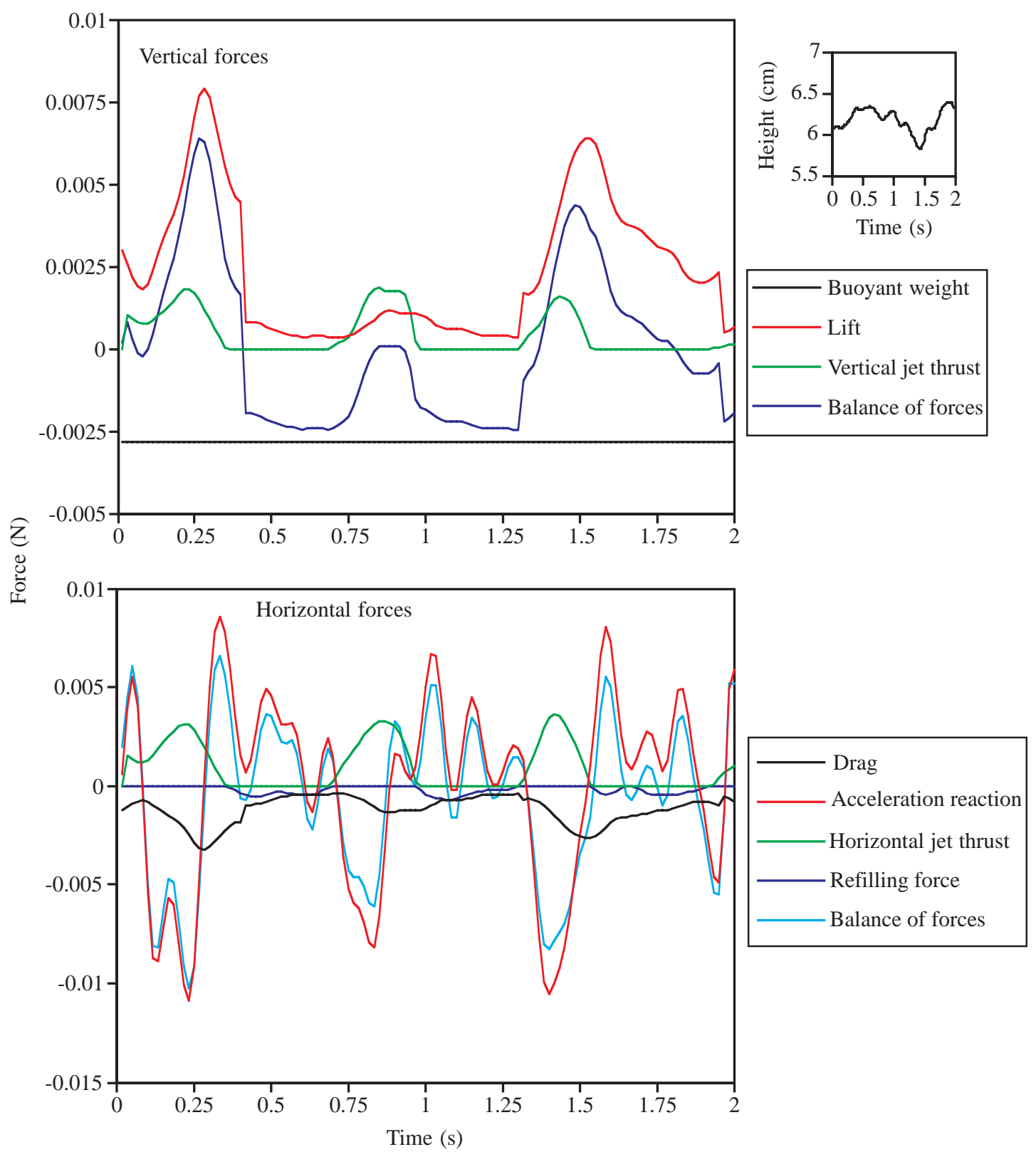

Fig. 10. Vertical and horizontal forces acting on a $4.4 \mathrm{~cm}$ Lolliguncula brevis swimming tail-first at $15 \mathrm{~cm} \mathrm{~s}^{-1}$. In the vertical forces graph, negative values represent forces acting towards the flume floor (i.e. buoyant weight), whereas in the horizontal forces graph negative values represent forces acting in the direction of the free-stream flow (e.g. drag). Since there was some net altitude change over the $2 \mathrm{~s}$ video sequence, the height of $L$. brevis above the flume floor is displayed next to the vertical forces graph. There was no net horizontal change over the video sequence. Fin thrust contributions are not included in the figure.

mantle and arms were positioned at high angles of attack that maximized lift but that also had relatively low lift-to-drag ratios. Thus, low-speed lift generation took precedence over low-speed drag reduction. In fact, up to $91 \%$ of the drag at speeds of $3-6 \mathrm{~cm} \mathrm{~s}^{-1}$ was associated with elevating the angle of attack of the mantle and arms. This finding is consistent with the hydrodynamic study of O'Dor (O'Dor, 1988) on Loligo opalescens, in which the maintenance of vertical position required $66-92 \%$ of the total force at $10 \mathrm{~cm} \mathrm{~s}^{-1}$, which was the lowest speed examined.
In addition to increasing the angle of attack of the mantle and arms, lift was generated by directing high-velocity jets of water downwards and by relying on fin activity. At $3-6 \mathrm{~cm} \mathrm{~s}^{-1}$, the funnel was positioned at very high angles of attack (frequently greater than $50^{\circ}$ ) while swimming both tail- and arms-first and, consequently, more jet thrust was directed vertically than horizontally. As pointed out by Vogel (Vogel, 1994) and evident from high low-speed energetic costs (Bartol et al., 2001b), directing a jet downwards is an inefficient method of hovering and maintaining vertical position. The fins 
were very active at low speeds, and vertical force imbalances indicated that the fins are responsible for as much as $83.8 \%$ of the vertical thrust at such speeds.

Positioning the body and appendages at high angles and actively moving the fins are critical for lift generation at low speeds; however, these behaviors may also be critical for stability control. The effectiveness of control surfaces on human-designed underwater vehicles, such as submarines and autonomous underwater vehicles [see Patterson and Sias (Patterson and Sias, 1998)], diminishes at low speeds when the forces generated by these surfaces become small compared with overall inertial forces. This also applies to fishes and squid. Positioning the body and appendages at high angles of attack increases drag, requiring the propulsors (i.e. fins) to beat more rapidly to provide more thrust. This increased thrust is better matched to body inertia, a force that can provide significant resistance to the return of aquatic organisms to desired paths at low speeds, and thus provides greater stability control (Webb, 1993; Webb, 2000). In addition to brief squid, increased body/arm angles of attack coupled with active fins at low speeds for purposes of stability control have been observed in neutrally buoyant fishes, such as trout and bluegill (Webb, 1993).

\section{Fin contribution to locomotion}

O'Dor (O'Dor, 1988) estimated that the fins of Loligo opalescens and Illex illecebrosus contribute 38 and $25 \%$, respectively, to overall horizontal thrust at the lowest speed considered in swimming analyses $\left(10 \mathrm{~cm} \mathrm{~s}^{-1}\right)$, but that the fins play no role in thrust production at higher speeds $\left(20-140 \mathrm{~cm} \mathrm{~s}^{-1}\right)$ since, at these speeds, fin trailing wave speeds are lower than swimming velocity. Moreover, Webber and O'Dor (Webber and O'Dor, 1986), O'Dor (O'Dor, 1988) and O'Dor and Webber (O'Dor and Webber, 1991) assumed that the fins of Loligo opalescens and Illex illecebrosus play only minor roles in lift generation and are used primarily for control and steering. For Lolliguncula brevis, which swims at lower sustained swimming speeds than Loligo opalescens or Illex illecebrosus, the fins appear to be important for both vertical and horizontal thrust production over a broad range of sustained swimming speeds, which is significant since fin activity is more economical than jetting (Hoar et al., 1994; Vogel, 1994). In the present study, the fins were used over $50-95 \%$ of the sustained speed range and could account for potentially as much as $83.8 \%$ of the total vertically directed force and $55.1 \%$ of the horizontal thrust.

Fin activity in Lolliguncula brevis cannot be characterized as strictly drag- or lift-based propulsion. In conventional dragbased propulsion, the fins move along an approximate anteroposterior axis in a 'rowing' motion, with the fins perpendicular to the direction of motion during the power stroke and parallel to the direction of motion during the recovery stroke. In lift-based fin propulsion, the fins move approximately parallel to a dorsoventral axis, and the angle of attack of the fins is adjusted during the fin-beat cycle so that positive thrust is achieved during both the upstroke and the downstroke (Vogel, 1994; Lauder and Jayne, 1996; Westneat,
1996). Brief squid fins flapped in a dorsoventral axis while a travelling wave moved in an anteroposterior direction. The presence of both a fin wave and fin flapping are typical of loliginids but not of ommastrephids, which use only dorsoventral flapping, or cuttlefish, which employ only an anteroposterior fin wave (Hoar et al., 1994). Furthermore, the pronounced sideways S-shaped fin wave observed at low speeds is more characteristic of drag-based propulsion, while the inverted V-shaped wave with distal portions positioned at obtuse angles relative to the oncoming flow observed at intermediate/high speeds resembles lift-based propulsion (Lauder and Jayne, 1996).

Drag-based propulsion is most effective at low speeds when the fin or fin wave moves backwards faster than the animal's forward progression (Westneat, 1996), while lift-based propulsion is most effective at higher speeds and when the local Reynolds number $(R e)$ of the fin is $>1000$ (Blake, 1983a; Webb and Weihs, 1986; Seibel et al., 1998). At low speeds, fin wave progression was greater than swimming speed, but at intermediate and high speeds, wave progression was less than swimming speed (even with an increase in fin speed with swimming velocity). Values of local $R e$ computed for the fins, using chord length as the length variable, are close to the $R e=1000$ transition; $R e$ approaches 1000 at $12,9,6$ and $3 \mathrm{~cm} \mathrm{~s}^{-1}$ for $1.0-2.9,3.0-4.9,5.0-6.9$ and $7.0-8.9 \mathrm{~cm} \mathrm{DML}$ squid, respectively. On the basis of the shape changes of the trailing fin wave with speed, variation in travelling wave speed relative to swimming speed and local fin Re near 1000, it is likely that squid fin movement involves both drag- and liftbased propulsive mechanisms, as has also been observed for pectoral fin activity in largemouth bass (Lauder and Jayne, 1996). Since drag and lift are both products of the same circulatory mechanisms, obscuring the line between drag- and lift-based mechanisms is not uncommon, especially when angles of attack are high in unsteady flows (Dickinson, 1996).

One caveat in suggesting that lift-based mechanisms occur in Lolliguncula brevis fin movement is that, at higher speeds when lift-based propulsive mechanisms were presumably operating, fin activity and amplitude decreased and eventually ceased in the tail-first swimming mode. Reduction and termination of fin activity at higher speeds is surprising given (i) that lift-based propulsion may still provide thrust at high speeds, even when fin wave speeds are lower than swimming speed and (ii) that the fins are more efficient than the jet since they provide continuous thrust and lift throughout the fin cycle and interact with larger volumes of water (Hoar et al., 1994; Vogel, 1994). O'Dor and Webber (O'Dor and Webber, 1991), who assumed that only drag-based fin propulsion is operating in squid, suggested that fin motion ceases when the undulatory waves cannot move backwards faster than the animal moves forwards because of limitations in shortening speeds of the obliquely striated muscle in the fin muscular hydrostat. If this is true, why is fin flapping/undulation used at all at speeds when swimming speed exceeds travelling wave speeds? O'Dor (O'Dor, 1988) found that the fin waves of Loligo opalescens frequently travel at speeds below swimming velocities, but 
suggested that thrust is still possible since fin activity occurs during refilling when the squid slows down. Although fin activity was sometimes observed in L. brevis during refilling at high speeds (when fin wave speed was lower than swimming speed), fin activity was more frequently observed during mantle contractions. As mentioned above, fin activity is probably a composite of drag- and lift-based propulsion, and conventional rules for either mechanism probably do not apply. The termination and reduction of fin activity may very well be related to the morphology and physiology of the fin muscular hydrostat (Kier, 1988; Kier, 1989) but, because both drag- and lift-based mechanisms probably underlie fin activity and squid are capable of making behavioral adjustments throughout the jet cycle, fin activity does not simply cease when swimming speeds exceed fin wave speeds.

\section{Locomotive efficiency}

Froude efficiencies $\left(\eta_{\mathrm{F}}\right)$ presented in this study for Lolliguncula brevis swimming tail-first $\left(\eta_{\mathrm{F}}=28.3-57.5 \%\right)$ are generally higher than those reported previously for Illex illecebrosus $\left(\eta_{\mathrm{F}}=12-34 \%\right)$ swimming over a range of speeds (O'Dor, 1988). The average Froude efficiency reported by Anderson and DeMont (Anderson and DeMont, 2000) for Loligo pealei swimming at $25 \mathrm{~cm} \mathrm{~s}^{-1}$ (approximately 1 mantle length $\mathrm{s}^{-1}$ ) was $56 \%$, which is close to Froude efficiencies of $42.4-57.5 \%$ for $L$. brevis swimming at $6-9 \mathrm{~cm} \mathrm{~s}^{-1}$ (1.1-1.6 mantle lengths $\left.\mathrm{s}^{-1}\right)$. Interestingly, Anderson and DeMont (Anderson and DeMont, 2000) suggest that Froude efficiency, which is the traditional measure of propulsive efficiency in jet-propelled organisms, underestimates efficiency during jetting and fails accurately to reflect the intake mechanism of the squid (i.e. in the Froude propulsion approach, the momentum of the fluid is continually added to the system and not brought to rest, as is the case for squid during refilling). Consequently, they suggest two alternative methods of computing propulsive efficiency in jet-propelled organisms: (i) rocket motor propulsive efficiency, which is presumably a better estimate of jet efficiency during fluid output than Froude efficiency, and (ii) whole-cycle propulsive efficiency, which more accurately reflects the balance of energy during fluid output and input than Froude efficiency. Both methods of evaluating efficiencies were calculated in the present study. Anderson and DeMont (Anderson and DeMont, 2000) determined that average rocket motor propulsive efficiency for Loligo pealei was $65 \%$, which is close to the upper limit of rocket propulsive efficiencies reported in this study for $L$. brevis swimming tail-first (rocket propulsive efficiencies for $L$. brevis were 32.1-69.4\%). These estimates of output efficiency are greater than Froude estimates and are closer to maximum propulsive efficiencies reported for fish (81\%) (Webb, 1971). Whole-cycle estimates computed by Anderson and DeMont (Anderson and DeMont, 2000) for L. pealei (34-48\%) were similar to whole-cycle efficiencies calculated in the present study for L. brevis (29.0-44.4\%). Both are generally lower than Froude and rocket motor efficiency estimates and suggest that the refilling period is costly for squid.
Although rocket motor propulsive efficiency and wholecycle propulsive efficiency arguably characterize the jet locomotive system in squid more effectively than Froude efficiency, none of the above efficiencies completely measure locomotor efficiency in squid. Squid rely on both the jet and their fins for locomotion and, when both are active (e.g. at low/intermediate speeds), the efficiencies above, which account only for jet thrust, do not accurately reflect locomotive efficiency. Active fins lower the thrust requirements of the jet and elevate efficiencies. For example, efficiencies determined during arms-first swimming, when the fins were most active and when the jet was generating the least amount of horizontal thrust, were consistently higher than during tail-first swimming. Furthermore, the highest efficiencies were detected at $9 \mathrm{~cm} \mathrm{~s}^{-1}$, when the fins were active and less downward thrust was necessary to counteract negative buoyancy compared with lower speeds. Therefore, when the fins are active, the above efficiencies should be viewed with caution, but when the fins are inactive, they are useful indicators of efficiency.

\section{Swimming strategies}

The greater preference for arms-first swimming at low speeds in swim tunnels followed by a transition to exclusive tail-first swimming at intermediate and high speeds indicates that there are velocity-specific advantages associated with each swimming mode. Tail-first swimming is probably more preferable at high speeds because the funnel does not need to bend to generate the necessary horizontal thrust. In arms-first swimming, the funnel must curve by approximately $180^{\circ}$ to direct thrust rearwards in a horizontal path, and lateral video views of the funnel indicate that some funnel constriction is concomitant with significant curvature. This constriction in the funnel significantly lowers expelled water volume flux $(J)$ since $J$ is proportional to the fourth power of funnel radius $(r)$ $\left[J=\left(\pi r^{4} / 8 \mu\right)(\Delta p / l)\right.$, where $\mu$ is the dynamic viscosity of water and $\Delta p / l$ is the pressure gradient (Denny, 1993)]. Therefore, water must be expelled at high velocity to produce thrust comparable with that generated by a non-constricted funnel. Since $E=1 / 2 m v^{2}$, where $E$ is energy, $m$ is mass and $v$ is velocity, and energy requirements scale with the square of expelled water velocity, jet-propelled swimming in an arms-first orientation at high speeds is energetically costly.

In L. brevis, funnel constriction during arms-first swimming is presumably most deleterious during the early portion of mantle contraction when the funnel expands to maximal diameter. During the remainder of the contraction cycle, $L$. brevis actively reduces funnel diameter. O'Dor (O'Dor, 1988) and Anderson and DeMont (Anderson and DeMont, 2000) detected similar dynamic control of the funnel in Loligo opalescens and Loligo pealei, respectively. Squid may be reducing funnel diameter at the end of the jet cycle to maximize power output from a given volume change.

During high-speed tail-first swimming, the fins may be used for forward attitude control, steering and lift generation, while the trailing arms, especially the third arms with heavy keels that are often spread out to act as high-aspect-ratio airfoils, may 
serve to stabilize the body, adjust pitch and make lift adjustments (as was observed during mantle refilling). During arms-first swimming, the arms, which are located at the leading edge, collapse into a conical arrangement and play less of a role in stabilization and lift adjustment.

There are benefits to arms-first swimming as well, especially at low speeds. Arms-first swimming allows for greater observance of forward surroundings than tail-first swimming, since the eyes are located more anteriorly and the arms may be moved if necessary for clearer forward views. Because prey strikes occur in an arms-first orientation (Hanlon and Messenger, 1996; Kier and van Leeuwen, 1997), arms-first swimming enables swift prey attacks whenever opportunities arise, while tail-first swimming requires rotation to arms-first swimming prior to attack. Arms-first swimming is also beneficial for defensive posturing during sudden encounters with predators (Hanlon and Messenger, 1996). While swimming arms-first, the fins are located near the trailing edge, which reduces interaction between the fin wake and the body, and this consequently enhances fin propulsion and efficiency (Lighthill and Blake, 1990; Daniel et al., 1992).

As mentioned above, maximizing fin propulsion and efficiency is advantageous since, unlike jet propulsion, fin locomotion provides continuous lift and thrust throughout the fin cycle and affects relatively large volumes of water with each fin stroke. Optimal fin placement, high fin thrust efficiency and volume flux limitations associated with funnel bending and jetting all contributed to greater reliance on fin propulsion and less on jetting during arms-first swimming. In fact, neither fin-beat frequency nor fin amplitude decreased appreciably with speed during arms-first swimming, as was observed in tail-first swimming, despite the fact that swimming speeds exceeded fin speeds at higher velocities. (This is further evidence that drag-based propulsion is not necessarily the only mechanism underlying fin motion in L. brevis.) The degree of funnel bending and volume flux limitations during arms-first swimming were reduced by positioning the funnel at high angles of attack (on average, funnel angles of attack were $15^{\circ}$ greater during arms-first swimming than during tail-first swimming) and relying on the jet more for vertical than for horizontal thrust. Because less dynamic lift from flow over the body was required when the funnel was positioned at high angles of attack during arms-first swimming, composite mantle/arm angles of attack were reduced (on average, composite angles were $6^{\circ}$ lower relative to tail-first swimming) and lift-to-drag ratios increased as profile drag and induced drag were reduced by the change in angle of attack. Most of the adjustment in angle of attack was achieved by lowering arm angles of attack and not mantle angles of attack.

No consistent increase in mantle contraction frequency, mantle expansion, fin activity, fin amplitude, fin speed or fin downstroke time with increasing speed was observed during arms-first swimming. Where then does the extra thrust come from to power locomotion at higher speeds? Unlike tail-first swimming, no one dominant mechanism was responsible for thrust elevation. An examination of the three squid considered in the force balance equations revealed that jet thrust did increase with speed but that the mechanism(s) responsible for this increase varied among squid and with speed. Jet thrust elevation was achieved using one or more of the following methods: (i) higher mantle contraction frequency, (ii) greater mantle expansion or (iii) lower funnel angles of attack. High variability in the mechanism(s) selected to achieve greater jet thrust coupled with limited arms-first data (a more restricted size range was considered for arms-first swimming than for tail-first swimming) made it difficult to detect consistent behavioral mechanisms for jet thrust enhancement. Furthermore, even though fin speed, fin-beat frequency and finbeat amplitude did not increase with speed, some additional horizontal thrust may be provided by keeping fin-beat frequency and amplitude high, lowering the angle of attack of the mantle to which the fins are attached and positioning the fins at various angles of attack to maximize lift-based propulsion.

O'Dor (O'Dor, 1988) reported four distinct gaits in $L$. opalescens during tail-first swimming that were related to the use of collagen springs in the mantle. In the present study, some similar behavioral transitions were detected in L. brevis during tail-first swimming, but overall behavioral changes tended to be more gradual over the sustained speed range considered, with behavioral differences most apparent when comparing size classes. For example, O'Dor (O’Dor, 1988) found that the amplitude of mantle expansion for L. opalescens was initially low at low speeds $\left(10 \mathrm{~cm} \mathrm{~s}^{-1}\right)$, but then increased significantly and remained constant over a broad range of speeds between 20 and $40 \mathrm{~cm} \mathrm{~s}^{-1}$, only to increase again at critical speeds of $50 \mathrm{~cm} \mathrm{~s}^{-1}$ and at burst speeds of $140 \mathrm{~cm} \mathrm{~s}^{-1}$. For brief squid, mantle expansion generally increased consistently with speed during tail-first swimming and did not remain constant over a broad range of speeds. One notable exception was squid in the $1.0-2.9 \mathrm{~cm} D M L$ size class, which did not vary the amplitude of mantle expansion significantly over the entire range of swimming speeds.

During tail-first swimming, angles of attack and fin-beat amplitude decreased linearly with speed for all size classes of brief squid, and mantle contraction frequency either remained constant (size classes $>3 \mathrm{~cm} D M L$ or more) or increased steadily with speed (size class $<3 \mathrm{~cm} D M L$ ). O'Dor (O'Dor, 1988) found that mantle contraction frequency of adult $L$. opalescens remains relatively constant with speed, and Webber and O'Dor (Webber and O'Dor, 1986) found that contraction frequency of Illex illecebrosus increases from 28 to $48 \mathrm{~cm} \mathrm{~s}^{-1}$ but that, above $48 \mathrm{~cm} \mathrm{~s}^{-1}$, contraction frequency increases less steeply or remains constant with elevated swimming speed. O'Dor (O'Dor, 1988) reported that the fins beat twice with each mantle contraction at $10 \mathrm{~cm} \mathrm{~s}^{-1}$, once during refilling over a broad range of speeds between 20 and $40 \mathrm{~cm} \mathrm{~s}^{-1}$, and not at all at both sustained and burst speeds above $50 \mathrm{~cm} \mathrm{~s}^{-1}$. In the present study, fin activity during tail-first swimming generally decreased linearly with swimming speed until sub-critical speeds, at which the fins simply wrapped around the mantle. The exception again was squid within the $1.0-2.9 \mathrm{~cm} D M L$ size 
class, which abruptly shifted from 2 fin beats s $\mathrm{s}^{-1}$ at $9 \mathrm{~cm} \mathrm{~s}^{-1}$ to none at $12 \mathrm{~cm} \mathrm{~s}^{-1}$. As mentioned above, fin flapping did sometimes coincide with refilling at intermediate speeds when fin activity was low, but fin flapping was more frequently coupled with mantle contraction at intermediate speeds. Moreover, at low speeds when fin activity was high, fin flapping was often coupled with both refilling and contraction. Finally, mantle refilling times were greater than mantle contraction times, as was suggested by O'Dor (O'Dor, 1988), but for most of the size classes, refilling did not occur progressively faster over a range of speeds. The exception was squid in the small size class $(1.0-2.9 \mathrm{~cm} D M L)$, which refilled and contracted their mantles progressively faster with swimming speed during tail-first swimming.

To swim at higher speeds, small squid $(D M L<3.0 \mathrm{~cm})$ swimming tail-first increased contraction frequency and kept mantle expansion relatively constant, whereas squid belonging to the larger size classes (DML $3.0 \mathrm{~cm}$ or more) increased mantle expansion and kept contraction rates relatively constant. The dichotomy in swimming approaches was probably not a result of differences in relative speed ranges. Although a broader range of relative swimming speeds was considered for squid less than $3 \mathrm{~cm}$ in $D M L$ $\left(1.25-6.37 D M L \mathrm{~s}^{-1}\right)$ than for squid more than $5 \mathrm{~cm}$ in $D M L$ (0.41-3.33 DML s $\left.{ }^{-1}\right)$, squid $3.0-4.9 \mathrm{~cm}$ in $D M L$ were examined over a similar speed range $\left(0.82-6.21 D M L \mathrm{~s}^{-1}\right)$ to that of smaller squid, yet did not increase mantle contraction frequency with speed. Furthermore, even within the speed range 0-3DML s ${ }^{-1}$, mantle contraction frequency for squid less than $3 \mathrm{~cm}$ in $D M L$ increased with speed, and mantle expansion was relatively constant.

The observed behavioral differences in swimming approaches among size classes do not appear to be related to the mantle musculature. Squid mantle tissue functions as a constant-volume system with a three-dimensional array of tightly bundled muscles commonly called a muscular hydrostat (Kier and Smith, 1985; Smith and Kier, 1989). When circular muscles shorten during mantle contraction, they increase in diameter, causing the mantle wall to thicken. Obliquely oriented collagen fibers traversing the thickness of the mantle wall are strained and store energy at times in the jet cycle when, because of the geometry of the locomotor apparatus, the circular muscles cannot do useful hydrodynamic work (Gosline and Shadwick, 1983; Pabst, 1996). Elastic energy stored in the collagen fibers powers much of the refilling phase of the jet cycle, although contraction of radially oriented muscle fibers, which extend from the inner to outer surface of the mantle, also plays a role in refilling (Gosline and Shadwick, 1983; Gosline et al., 1983; Kier, 1988). The elastic spring system within the mantle is non-resonant, depending simply on the degree of loading by the circular muscles, and the system does not have to be driven at or near its natural frequency, as is the case with hydromedusan jellyfish (DeMont and Gosline, 1988; Pabst, 1996). Therefore, the constant rates of mantle contraction observed in larger squid are probably not the products of a resonant elastic spring system. There are ontogenetic differences in the arrangement, mechanical properties and physiological properties of the mantle musculature of squid, especially mantle connective tissue (Thompson, 1997; Thompson, 1998), but these differences contribute to reduced mantle expansion and increased muscle shortening with age (size). Therefore, these differences do not help explain the observed dichotomy in swimming strategies.

\section{Unsteady mechanisms}

The differences in contraction rates and swimming strategies may relate to hydrodynamics and vortex ring formation, which was observed in L. brevis. Our current understanding of vortex ring phenomena is reviewed nicely by Shariff and Leonard (Shariff and Leonard, 1992) and Lim and Nickels (Lim and Nickels, 1995). In the context of jet propulsion, vortex rings are beneficial because they entrain additional water from surrounding areas and increase the amount of fluid driven backwards in the jet wake. Since jet thrust is the product of the mass (per unit time) and the velocity of water expelled backwards, additional ambient water accelerated by the vortex rings may elevate thrust. This was demonstrated experimentally by Krueger (Krueger, 2001), who found that the impulse associated with vortex ring formation is significantly larger than that expected from the jet velocity alone. Interestingly, Gharib et al. (Gharib et al., 1998) demonstrated that there is a limit to the amount of energy or circulation that enters a developing vortex ring during jetting. This limit occurs when the ratio of the length $(l)$ of a plug of fluid forced through a tube to the diameter $d$ of the tube is 3.6-4.5, which is known as the formation number. When the l/d ratio (stroke ratio) is greater than approximately 4, the vortex ring no longer grows in strength but rather 'pinches off' from the jet, and the remaining fluid in the pulse is simply ejected as a trailing jet. This pinch off phenomenon also has significance for propulsion since it was shown that the formation of a vortex ring generates proportionally more impulse per unit of ejected fluid than does a trailing jet (Krueger, 2001).

Given that funnel diameter $(d)$ and expelled water volume $(v)$ were known in our experiment, $l / d$ ratios could be calculated for $L$. brevis from $v=\pi / 4\left(d^{2}\right) l$. Large and intermediate-sized squid generally had $l / d$ ratios far in excess of 4 , ranging from 10 to 40 . However, smaller squid $(D M L<3.0 \mathrm{~cm})$, which have larger relative funnel diameters, had lower $l / d$ ratios overall, ranging from 3 to 17 ; some smaller squid even kept formation numbers between 4 and 7 throughout various jet cycles. Consequently, by keeping expelled water volume low and increasing mantle contraction rates with speed, smaller squid may be maximizing impulse per unit time and possibly for a given energy input. Simply keeping the spacing between vortex rings low by increasing contraction rates with speed may also improve thrust. Weihs (Weihs, 1977) suggests that propulsive benefits increase as pulse rate increases and separation between vortex rings decreases because vortices are able to interact, producing a greater overall translational velocity. Smaller squid 
that have relatively larger funnel orifices and that expel relatively small volumes of water at high frequency may benefit from this vortex ring interaction. Conversely, larger squid that expel larger volumes of water at high speeds through relatively small funnel diameters probably produce vortex rings that are too widely spaced to benefit significantly from ring interaction. Thus, increasing mantle contraction rate (to keep ring spacing low) with speed presumably does not augment thrust significantly for intermediate/large squid, allowing for the selection of more cost-effective mechanisms for increasing thrust with speed, such as increasing expelled water volume. Interestingly, other studies have suggested that thrust benefits may actually be reduced at high pulse rates because vortex rings begin to interfere negatively with each other (Krueger, 2001). Clearly, quantitative measurement of the wake structure of squid of different sizes, using techniques such as twodimensional digital particle image velocimetry and threedimensional defocusing digital particle image velocimetry (Pereira et al., 2000), is necessary to test the above hypotheses and measure jet wake structure.

Since squid rely on a pulsating jet for propulsion, they swim in an unsteady fashion, constantly accelerating and decelerating as they move through the water and experience a force known as the acceleration reaction, which resists changes in the animal's velocity (Batchelor, 1967; Webb, 1979; Daniel, 1983; Daniel, 1984; Daniel, 1985; Vogel, 1994). In his work with jetting medusae, Daniel (Daniel, 1983; Daniel, 1984) found that the acceleration reaction is an important instantaneous force, often far outweighing drag at a given point in the jet cycle, but that the relative contribution of the acceleration reaction averaged over a jet cycle is much smaller. Moreover, when starting from rest, the relative importance of the acceleration reaction in resisting movement averaged over a jet cycle is approximately $50 \%$, but after several jet cycles the acceleration reaction contributes less than $5 \%$ of resistance. This is because the acceleration reaction resists both acceleration and deceleration and, consequently, changes direction during the cycle. During steady swimming, mean acceleration and deceleration should balance out over a cycle or the organism would increase or decrease velocity, respectively. Therefore, the net acceleration reaction over the cycle should approach zero.

As was the case with Daniel's (Daniel, 1983; Daniel, 1984) work with swimming medusae, the acceleration reaction of $L$. brevis was the most important instantaneous force during the jet cycle, and the relative contributions of the acceleration reaction averaged over a cycle were much smaller than the instantaneous contributions. The instantaneous contribution of the acceleration reaction was even greater relative to instantaneous drag (and lift) for L. brevis, which positions its mantle, arms and fins at various angles of attack, than reported by Daniel (Daniel, 1983; Daniel, 1984) for medusae, which swam in a horizontal orientation. The added mass coefficients reported in the present study for squid at high angles of attack are larger than those reported for other biological organisms (Denny, 1988; Daniel, 1983). Thus, there is some concern that interactions between the model and the flume walls at high angles of attack (when the models were closer to the wall) may have elevated force measurements, as observed by Sarpkaya (Sarpkaya, 1976) for cylinders near solid surfaces. If interactive effects confounded high-angle force measurements, then acceleration reaction measurements at low speeds may be high; however, at higher speeds when angles of attack were lower, added mass coefficients were within the range of those of other biological organisms, and the acceleration reaction was still the dominant instantaneous force. The net acceleration reaction did not approach zero over several jet cycles as predicted by Daniel (Daniel, 1983; Daniel, 1984), especially as the speed and the range of accelerations and decelerations increased. However, this is not surprising given that measurement errors are often magnified when taking the second derivative of positional changes (even those that have been smoothed) to compute acceleration.

Unsteady aspects of flow probably affect other components of thrust and lift production in L. brevis. As discussed above, jets pulsed at certain frequencies may have advantages over continuous, steady jets. Anderson and DeMont (Anderson and DeMont, 2000) demonstrate that peak thrust predictions using an unsteady approach are better matched to axial velocities than quasi-steady approaches, and unsteady analyses predict negative jet pressures in the mantle near the end of the jet period that are not predicted using quasi-steady methods. Using three-dimensional kinematic data, bio- and hydromechanical modeling and/or electromyography, Daniel (Daniel, 1988), Lauder and Jayne (Lauder and Jayne, 1996) and Westneat (Westneat, 1996) offer evidence that the acceleration reaction provides propulsive thrust during fin motion in fishes both during dorsoventral flapping and during anteroposterior rowing. Dickinson and Götz (Dickinson and Götz, 1996), using sensitive force measurement and flow visualization equipment, demonstrated that unsteady movements in insect wings dramatically elevate lift and thrust. Given that flow around squid fins is unsteady as a result of pulsatile swimming and fin velocity changes during upstrokes and downstrokes, unsteady flow components assuredly affect vertical and horizontal fin thrust, although the effects were not examined directly in the present study. Unsteady movements of the arms, appendages that have been largely ignored in other squid swimming studies, also are intriguing. The arms of L. brevis are sometimes positioned at very high angles of attack, which produces flow separation and the likely development of attached bubble vortices that may produce added lift for the head. Unsteady jetting movements coupled with rapid arm oscillation from high to low angles of attack (behaviors that were often observed in L. brevis) may help generate, stabilize and retain these attached vortices, as oscillating wings in insects do to provide thrust and lift enhancement (Dickinson and Götz, 1996).

\section{Concluding remarks}

The data presented above provide an overview of the swimming behavior and mechanics of a slow-swimming squid, Lolliguncula brevis, over a range of sizes and speeds and at various swimming orientations. On the basis of the results of 
this study, L. brevis clearly uses complex interactions between the mantle, fins, arms and funnel during locomotion. Given that the interactive behaviors occur in unsteady flows, it is of great interest to determine next what impact these behaviors have on the surrounding fluid medium. Using two-dimensional digital particle image velocimetry, which has been used in recent fish studies (Stamhuis and Videler, 1995; Müller et al., 1997; Drucker and Lauder, 1999), and new three-dimensional defocusing digital particle image velocimetry technology (Pereira et al., 2000) to study flow around aquatic organisms is promising and should yield useful insight into temporal and spatial hydrodynamic variation. When wake features around the fins, arms, mantle and funnel are understood, we may then begin to form explicit links between kinematics, force production and fluid mechanics, which will be critical for understanding squid locomotion.

Intellectual input and critical reviews of this manuscript by W. M. Kier, M. Vecchione and M. Luckenbach are gratefully acknowledged. Special thanks to S. L. Sanderson for the use of video cameras and motion-analysis equipment and valuable comments on earlier drafts and to M. Gharib for useful discussions and access to his laboratory at the California Institute of Technology. We thank R. Kraus, G. Coates, J. Gelsleichter, S. Moein Bartol, D. Carlini, T. MacDonald, M. Southworth, S. Gaichas, M. Wagner and K. Walker for field assistance, W. Reisner and R. Bonniwell for machining and the VIMS Oyster hatchery staff for maintenance of live organisms. This study was supported in part by the LernerGray Fund for Marine Research, VIMS/SMS Minor Research Grants, the Eastern Shore Corporate Scholarship, Newport News Shipbuilding and NASA Langley Research Center. Financial support during the writing phase of this project was provided by the Office of Naval Research under contract N00014-96-0607 to M. S. Gordon.

\section{References}

Anderson, E. J. and DeMont, M. E. (2000). The mechanics of locomotion in the squid Loligo pealei: locomotory function and unsteady hydrodynamics of the jet and intramantle pressure. J. Exp. Biol. 203, 2851-2863.

Bartol, I. K., Mann, R. and Vecchione, M. (2001a). Distribution of the euryhaline squid Lolliguncula brevis in the Chesapeake Bay: Effects of selected abiotic factors. Mar. Ecol. Prog. Ser. (in press).

Bartol, I. K., Mann, R. and Patterson, M. R. (2001b). Respiratory costs of the negatively buoyant squid Lolliguncula brevis. J. Exp. Biol. 204, 3639-3653.

Batchelor, G. K. (1967). An Introduction to Fluid Dynamics. London: Cambridge University Press.

Bertin, J. J. and Smith, M. L. (1989). Aerodynamics for Engineers. Englewood Cliffs, NJ: Prentice Hall.

Blake, R. W. (1983a). Fish Locomotion. London: Cambridge University Press.

Blake, R. W. (1983b). Median and paired fin propulsion. In Fish Biomechanics (ed. P. W. Webb and D. Weihs), pp. 214-247. New York: Praeger Publishers.

Brett, J. R. (1964). The respiratory metabolism and swimming performance of young sockeye salmon. J. Fish. Res. Bd. Can. 21, 1183-1226.

Chamberlain, J. A., Jr (1976). Flow patterns and drag coefficients of cephalopod shells. Palaeontology 19, 539-563.

Chamberlain, J. A., Jr (1980). The role of body extension in cephalopod locomotion. Palaeontology 23, 445-461.
Chamberlain, J. A., Jr (1981). Hydromechanical design of fossil cephalopods. Syst. Ass. Spec. 18, 289-336.

Chamberlain, J. A., Jr (1990). Jet propulsion of Nautilus: a surviving example of early Paleozoic cephalopod locomotor design. Can. J. Zool. 68, 806-814. Chamberlain, J. A. and Westerman, G. E. (1976). Hydrodynamic properties of cephalopod shell ornament. Paleobiology 2, 316-331.

Cheng, J.-Y., Davison, I. G. and DeMont, M. E. (1996). Dynamics and energetics of scallop locomotion. J. Exp. Biol. 199, 1931-1946.

Cheng, J.-Y. and DeMont, M. E. (1996). Hydrodynamics of scallop locomotion: unsteady forces on clapping shells. J. Fluid Mech. 317, 73-90.

Dadswell, M. J. and Weihs, D. (1990). Size-related hydrodynamic characteristics of the giant scallop Placopecten magellanicus (Bivalvia: Pectinidae). Can. J. Zool. 68, 778-785.

Daniel, T. L. (1983). Mechanics and energetics of medusan jet propulsion. Can. J. Zool. 61, 1406-1420.

Daniel, T. L. (1984). Unsteady aspects of aquatic locomotion. Am. Zool. 24, 121-134.

Daniel, T. L. (1985). Cost of locomotion: unsteady medusan swimming. $J$. Exp. Biol. 119, 149-164.

Daniel, T. L. (1988). Forward flapping flight from flexible fins. Can. J. Zool. 66, 630-638.

Daniel, T. L., Jordan, C. and Grunbaum, D. (1992). Hydromechanics of swimming. In Advances in Comparative and Environmental Physiology, vol. 11 (ed. R. McN. Alexander), pp. 17-49. Berlin: Springer-Verlag.

DeMont, M. E. and Gosline, J. M. (1988). Mechanics of jet propulsion in the hydromedusan jellyfish Polyorchis penicillatus. II. Energetics of the jet cycle. J. Exp. Biol. 134, 333-345.

Denny, M. W. (1988). Biology and Mechanics of the Wave-Swept Environment. Princeton, NJ: Princeton University Press.

Denny, M. W. (1993). Air and Water: The Biology and Physics of Life's Media. Princeton, NJ: Princeton University Press.

Dickinson, M. H. (1996). Unsteady mechanisms of force generation in aquatic and aerial locomotion. Am. Zool. 36, 537-554.

Dickinson, M. H., Farley, C. T., Full, R. J., Koehl, M. A. R., Kram, R. and Lehman, S. (2000). How animals move: an integrative view. Science $\mathbf{2 8 8}$, 100-106.

Dickinson, M. H. and Götz, K. G. (1996). The wake dynamics and flight forces of the fruit fly Drosophila melanogaster. J. Exp. Biol. 199, 2085-2104.

Drucker, E. G. and Lauder, G. V. (1999). Locomotor forces on a swimming fish: three-dimensional vortex wake dynamics quantified using digital particle image velocimetry. J. Exp. Biol. 202, 2393-2412.

Ellington, C. P. (1984). The aerodynamics of insect flight. I-IV. Phil. Trans. R. Soc. Lond. B 305, 1-181.

Finke, E. H., Pörtner, H. O., Lee, P. G. and Webber, D. M. (1996). Squid (Lolliguncula brevis) life in shallow waters: oxygen limitation of metabolism and swimming performance. J. Exp. Biol. 199, 911-921.

Fish, F. E. (1987). Kinematics and power output of jet propulsion by the frogfish genus Anternnarius (Lophiiformes: Anternnariidae). Copeia 1987, 1046-1048.

Gharib, M., Rambod, E. and Shariff, K. (1998). A universal time scale for vortex ring formation. J. Fluid Mech. 360, 121-140.

Gosline, J. M. and Shadwick, R. E. (1983). The role of elastic energy storage mechanisms in swimming: an analysis of mantle elasticity in escape jetting in the squid, Loligo opalescens. Can. J. Zool. 61, 1421-1431.

Gosline, J. M., Steeves, J. D., Harman, A. D. and DeMont, M. E. (1983). Patterns of circular and radial mantle activity in respiration and jetting in the squid Loligo opalescens. J. Exp. Biol. 104, 97-109.

Hamming, R. W. (1983). Digital Filters. Englewood Cliffs, NJ: Prentice-Hall. Hanlon, R. T., Hixon, R. F. and Hulet, W. H. (1983). Survival, growth and behavior of the loliginid squid Loligo plei, Loligo pealei and Lolliguncula brevis (Mollusca: Cephalopoda) in closed sea water systems. Biol. Bull. 165, $637-685$.

Hanlon, R. T. and Messenger, J. B. (1996). Cephalopod Behaviour. Cambridge: Cambridge University Press. 232pp.

He, P. and Wardle, C. S. (1986). Tilting behavior of the Atlantic mackeral, Scomber scombrus, at low swimming speeds. J. Fish Biol. 29, 223-232.

Heine, C. (1992). Mechanics of flapping fin locomotion in the cownose ray, Rhinoptera bonasus (Elasmobrachii: Myliobatidae). PhD dissertation, Duke University, Durnham, NC. 286pp.

Hendrix, J. P., Jr, Hulet, W. H. and Greenberg, M. J. (1981). Salinity tolerances and the responses to hypoosmotic stress of the bay squid Lolliguncula brevis, a euryhaline cephalopod mollusc. Comp. Biochem. Physiol. 69A, 641-648. 
Hixon, R. F. (1980). Growth, reproductive biology, distribution and abundance of three species of loliginid squid (Myopsida, Cephalopoda) in the northwest Gulf of Mexico. PhD dissertation, University of Miami, FL. 182pp.

Hixon, R. F. (1983). Loligo opalescens. In Cephalopod Life Cycles, vol. 1, Species Accounts (ed. P. R. Boyle), pp. 95-114. London: Academic Press.

Hoar, J. A., Sim, E., Webber, D. M. and O'Dor, R. K. (1994). The role of fins in the competition between squid and fish. In Mechanics and Physiology of Animal Swimming (ed. L. Maddock, Q. Bone and J. M. V. Rayner), pp. 27-33. Cambridge: Cambridge University Press.

Holland, C. H. (1987). The nautiloid cephalopods: a strange success. J. Geol. Soc., Lond. 144, 1-15.

Jackson, K. M. (1979). Fitting of mathematical functions to biomechanical data. IEEE Trans Biomed. Engng. 26, 122-124.

Johnson, W., Soden, P. D. and Trueman, E. R. (1972). A study in jet propulsion: an analysis of the motion of the squid, Loligo vulgaris. J. Exp. Biol. 56, 155-165.

Kier, W. M. (1988). The arrangement and function of molluscan muscle. In The Mollusca, Form and Function, vol. 11 (ed. E. R. Trueman and M. R. Clarke), pp. 211-252. New York: Academic Press.

Kier, W. M. (1989). The fin musculature of cuttlefish and squid (Mollusca, Cephalopoda): morphology and mechanics. J. Zool., Lond. 217, 23-38.

Kier, W. M. and Smith, K. K. (1985). Tongues, tentacles and trunks: the biomechanics of movement in muscular hydrostats. Zool. J. Linn. Soc. 83, 307-324.

Kier, W. M. and van Leeuwen, J. L. (1997). A kinematic analysis of tentacle extension in the squid Loligo pealei. J. Exp. Biol. 200, 41-53.

Krueger, P. (2001). The significance of vortex ring formation and nozzle exit over-pressure in pulsatile jet propulsion. PhD dissertation, California Institute of Technology, Pasadena, CA.

Kundu, P. K. (1990). Fluid Mechanics. San Diego, CA: Academic Press.

Lauder, G. V. and Jayne, B. C. (1996). Pectoral fin locomotion in fishes: testing drag-based models using three-dimensional kinematics. Am. Zool. 36, 567-581.

Lehmann, F.-O. and Dickinson, M. H. (1997). The changes in power requirements and muscle efficiency during elevated force production in the fruit fly, Drosophila melanogaster. J. Exp. Biol. 200, 1133-1134.

Lighthill, M. J. and Blake, R. W. (1990). Biofluiddynamics of balistiform and gymnotiform locomotion. Part 1. Biological background and analysis by elongated body theory. J. Fluid Mech. 212, 183-207.

Lim, T. T. and Nickels, T. B. (1995). Vortex rings. In Vortices in Fluid Flows (ed. S. I. Green), pp. 95-153. Dordrecht: Kluwer.

Lisoski, D. (1993). Nominally two-dimensional flow about a normal flat plate. $\mathrm{PhD}$ dissertation, California Institute of Technology, Pasadena, CA.

Madin, L. P. (1990). Aspects of jet propulsion in salps. Can. J. Zool. 68, 765-777.

Mangum, C. P. (1991). Salt sensitivity of the hemocyanin of eury- and stenohaline squid. Comp. Biochem. Physiol. 19A, 159-161.

Messenger, J. B., Nixon, M. and Ryan, K. P. (1985). Magnesium chloride as an anaesthetic for cephalopods. Comp. Biochem. Physiol. 82C, 203-205.

Millward, A. and Whyte, M. A. (1992). The hydrodynamic characteristics of six scallops of the Super Family Pectinacea, Class Bivalvia. J. Zool., Lond. 227, 547-566.

Müller, U. K., van den Heuvel, B. L. E., Stamhuis, E. J. and Videler, J. J. (1997). Fish footprints: morphology and energetics of the wake behind a continuously swimming mullet (Chelon labrosus Risso). J. Exp. Biol. 200, 2893-2906.

Munson, B. R. and Cronin, D. J. (1998). Airfoils and wings. In The Handbook of Fluid Dynamics (ed. R. W. Johnson), pp 43-1-43-8. New York: CRC Press.

Nachtigall, W. and Hanauer-Thieser, U. (1992). Flight of the honeybee. V. Drag and lift coefficients of the bee's body: implications for flight dynamics. J. Comp. Physiol. B 162, 267-277.

O'Dor, R. K. (1982). Respiratory metabolism and swimming performance of the squid, Loligo opalescens. Can. J. Fish. Aquat. Sci. 39, 580-587.

O'Dor, R. K. (1983). Illex illecebrosus. In Cephalopod Life Cycles, vol. 1, Species Accounts (ed. P. R. Boyle), pp. 95-114. New York: Academic Press.

O'Dor, R. K. (1988). Forces acting on swimming squid. J. Exp. Biol. 137, 421-442.

O'Dor, R. K., Balch, N., Foy, E. A. and Helm, P. L. (1985). The locomotion and energetics of hatchling squid, Illex illecebrosus. Am. Mal. Bull. 4, 55-60.

O'Dor, R. K., Hoar, J. A., Webber, D. M., Carey, F. G., Tanaka, S., Martins, H. R. and Porteiro, F. M. (1994). Squid (Loligo forbesi) performance and metabolic rates in nature. Mar. Fresh. Behav. Physiol. 25, $163-177$.

O'Dor, R. K. and Webber, D. M. (1986). Monitoring the metabolic rate and activity of free-swimming squid with telemetered jet pressure. J. Exp. Biol. 126, 205-224.

O'Dor, R. K. and Webber, D. M. (1991). Invertebrate athletes: tradeoffs between transport efficiency and power density in cephalopod evolution. $J$. Exp. Biol. 160, 93-112.

O'Dor, R. K., Wells, J. and Wells, M. J. (1990). Speed, jet pressure and oxygen consumption relationships in free-swimming Nautilus. J. Exp. Biol. 154, 383-396.

Orth, R. J., Luckenbach, M. W. and Moore, K. A. (1994). Seed dispersal in a marine macrophyte: implications for colonization and restoration. Ecology 75, 1927-1939.

Pabst, D. A. (1996). Springs in swimming animals. Am. Zool. 36, 723-735.

Patterson, M. R. (1984). Patterns of whole colony prey capture in the octocoral, Alcyonium siderium. Biol. Bull. 167, 613-629.

Patterson, M. R. and Sias, J. H. (1998). Fetch! ${ }^{\circledR}$ commercial autonomous underwater vehicle: a modular, platform-independent architecture using desktop personal computer technology. In Ocean Community Conference '98 Proceedings, vol. 2, pp. 891-897. Marine Technology Society Annual Conference, November 16-19, 1998, Baltimore, MD.

Pereira, F., Gharib, M., Dabiri, D. and Modarress, D. (2000). Defocusing DPIV: A 3-component 3-D DPIV measurement technique. Application to bubbly flows. Exp. Fluids 29, S078-S084.

Raup, D. M. (1967). Geometric analysis of shell coiling: coiling in ammonoids. J. Paleontol. 41, 43-65.

Rayner, J. M. V. (1979). A new approach to animal flight mechanics. J. Exp. Biol. 80, 17-54.

Sarpkaya, T. (1976). Forces on cylinders near a plane boundary in a sinusoidally oscillating fluid. Trans. ASME J. Fluid Engng. 98, 499-505.

Seibel, B. A., Thuesen, E. V. and Childress, J. J. (1998). Flight of the vampire: Ontogenetic gait-transition in Vampyroteuthis infernalis (Cephalopoda: Vampyromorpha). J. Exp. Biol. 201, 2413-2424.

Shariff, K. and Leonard, A. (1992). Vortex rings. Annu. Rev. Fluid Mech. 24, 235-279.

Smith, K. K. and Kier, W. M. (1989). Trunks, tongues and tentacles: moving with skeletons of muscle. Am. Sci. 77, 28-35.

Spedding, G. R., Rayner, J. M. V. and Pennycuick, C. J. (1984). Momentum and energy in the wake of a pigeon (Columba livia) in slow flight. J. Exp. Biol. 111, 81-102.

Stamhuis, E. J. and Videler, J. J. (1995). Quantitative flow analysis around aquatic animals using laser sheet particle image velocimetry. J. Exp. Biol. 198, 283-294.

Thompson, J. T. (1997). Changes in squid mantle kinematics during ontogeny: consequences for mantle connective tissue architecture. Am. Zool. 37, 79A.

Thompson, J. T. (1998). Ontogenetic changes in mantle kinematics in the squid, Sepioteuthis lessoniana. Am. Zool. 38, 20A.

Tobalske, B. W. and Dial, K. P. (1996). Flight kinematics of black-billed magpies and pigeons over a wide range of speeds. J. Exp. Biol. 199, $263-280$.

Trueman, E. R. (1975). The Locomotion of Soft-Bodied Animals. London: Edward Arnold.

Vecchione, M. (1991). Dissolved oxygen and the distribution of euryhaline squid Lolliguncula brevis. Bull. Mar. Sci. 49, 668-669.

Vecchione, M. and Roper, C. F. E. (1991). Cephalopods observed from submersibles in the Western North Atlantic. Bull. Mar. Sci. 49, 433-445.

Vogel, S. (1985). Flow-assisted shell reopening in swimming scallops. Biol Bull. 169, 624-630.

Vogel, S. (1994). Life in Moving Fluids. Second edition. Princeton, NJ: Princeton University Press. 467pp.

Vogel, S. and LaBarbera, M. (1978). Simple flow tanks for research and teaching. BioScience 28, 638-643.

Walker, J. A. (1998). Estimating velocities and accelerations of animal locomotion: a simulation experiment comparing numerical differentiation algorithms. J. Exp. Biol. 201, 981-995.

Ward-Smith, A. J. and Clements, D. (1982). Experimental determinations of the aerodynamic characteristics of ski-jumpers. Aeronaut. J. 86, 384-391.

Webb, P. W. (1971). The swimming energetics of trout. I. Thrust and power output at cruising speeds. J. Exp. Biol. 55, 489-520.

Webb, P. W. (1979). Mechanics of escape responses in crayfish (Orconectes virilis). J. Exp. Biol. 79, 245-263.

Webb, P. W. (1993). Is tilting behaviour at low swimming speeds unique to 


\section{I. K. Bartol, M. R. Patterson and R. Mann}

negatively buoyant fish? Observations on steelhead trout, Oncorhyncus mykiss and bluegill, Lepomis macrochirus. J. Fish Biol. 43, 687-694.

Webb, P. W. (2000). Maneuverability versus stability? Do fish perform well in both? In Proceedings of the First International Symposium on Aqua BioMechanisms/International Seminar on Aqua Bio-Mechanisms (ed. M. Nagai), pp. 21-29. August 27-30, 2000, Tokai University Pacific Center, Honolulu, Hawaii.

Webb, P. W. and Weihs, D. (1986). Functional locomotor morphology of early life history stages of fishes. Trans. Am. Fish. Soc. 115, 115-127.

Webber, D. M. and O'Dor, R. K. (1985). Respiration and swimming performance of short-finned squid (Illex illecebrosus). Scientific Council Studies. Northw. Atl. Fish. Org. 9, 133-138.

Webber, D. M. and O'Dor, R. K. (1986). Monitoring the metabolic rate and activity of free-swimming squid with telemetered jet pressure. J. Exp. Biol. 126, 205-224.

Weihs, D. (1977). Periodic jet propulsion of aquatic creatures. Fortschr. Zool. 24, 171-175.

Westneat, M. W. (1996). Functional morphology of aquatic flight in fishes: kinematics, electromyography and mechanical modeling of labriform locomotion. Am. Zool. 36, 582-598. 